\title{
A New Iterative Scheme for Generalized Mixed Equilibrium, Variational Inequality Problems, and a Zero Point of Maximal Monotone Operators
}

\author{
Kriengsak Wattanawitoon ${ }^{1,2}$ and Poom Kumam ${ }^{3}$ \\ ${ }^{1}$ Department of Mathematics and Statistics, Faculty of Science and Agricultural Technology, \\ Rajamangala University of Technology Lanna Tak, Tak 63000, Thailand \\ ${ }^{2}$ Centre of Excellence in Mathematics, CHE, Si Ayuthaya Road, Bangkok 10400, Thailand \\ ${ }^{3}$ Department of Mathematics, Faculty of Science, King Mongkut's University of Technology Thonburi \\ (KMUTT), Bangmod, Thungkru, Bangkok 10140, Thailand
}

Correspondence should be addressed to Poom Kumam, poom.kum@kmutt.ac.th

Received 3 November 2011; Accepted 16 November 2011

Academic Editor: Yonghong Yao

Copyright (C) 2012 K. Wattanawitoon and P. Kumam. This is an open access article distributed under the Creative Commons Attribution License, which permits unrestricted use, distribution, and reproduction in any medium, provided the original work is properly cited.

The purpose of this paper is to introduce a new iterative scheme for finding a common element of the set of solutions of generalized mixed equilibrium problems, the set of solutions of variational inequality problems, the zero point of maximal monotone operators, and the set of two countable families of quasi- $\phi$-nonexpansive mappings in Banach spaces. Moreover, the strong convergence theorems of this method are established under the suitable conditions of the parameter imposed on the algorithm. Finally, we apply our results to finding a zero point of inverse-strongly monotone operators and complementarity problems. Our results presented in this paper improve and extend the recently results by many others.

\section{Introduction}

Equilibrium problem theory is the most important area of mathematical sciences and widely popular among mathematicians and researchers in other fields due to its applications in a wide class of problems which arise in economics, finance, optimization, network and transportation, image reconstruction, ecology, and many others. It has been improved and extended in many directions. Furthermore, equilibrium problems are related to the problem of finding fixed point of nonexpansive mappings. In this way, they have been extensively studied by many authors; see [1-9]. They introduced new iterative schemes for finding a common element of the set of the solutions of equilibrium problems and the set of fixed points. In this paper, we are interested a new hybrid iterative method for finding a common elements of the set of solutions of generalized mixed equilibrium problems, the set of 
solutions of variational inequality problems, the zero point of maximal monotone operators, and the set of two countable families of quasi- $\phi$-nonexpansive mappings in the framework of Banach spaces.

Let $E$ be a Banach space with norm $\|\cdot\|$ and $C$ a nonempty closed convex subset of $E$ and let $E^{*}$ denote the dual of $E$.

A mapping $S: C \rightarrow C$ is said to be

(1) nonexpansive [1] if $\|S x-S y\| \leq\|x-y\|$ for all $x, y \in C$,

(2) relatively nonexpansive [10-12] if $\widehat{F(S)}=F(S)$ and $\phi(p, S x) \leq \phi(p, x)$ for all $x \in C$ and $p \in F(S)$, where the functional $\phi$ defined by (2.6). The asymptotic behavior of a relatively nonexpansive mapping was studied in $[13,14]$,

(3) $\phi$-nonexpansive, if $\phi(S x, S y) \leq \phi(x, y)$ for $x, y \in C$,

(4) quasi- $\phi$-nonexpansive if $F(S) \neq \emptyset$ and $\phi(p, S x) \leq \phi(p, x)$ for $x \in C$ and $p \in F(S)$.

In the sequel, we denote $F(T)$ as the set of fixed points of $S$. If $C$ is a bounded closed convex set and $S$ is a nonexpansive mapping of $C$ into itself, then $F(S)$ is nonempty (see [15]).

A point $p$ in $C$ is said to be an asymptotic fixed point of $S$ [16] if $C$ contains a sequence $\left\{x_{n}\right\}$ which converges weakly to $p$ such that $\lim _{n \rightarrow \infty}\left\|x_{n}-S x_{n}\right\|=0$. The set of asymptotic fixed points of $S$ will be denoted by $\widehat{F(S)}$.

Let $B$ be an operator from $C$ into $E^{*}$, and $B$ is said to be $\alpha$-inverse-strongly monotone if there exists a positive real number $\alpha$ such that

$$
\langle x-y, B x-B y\rangle \geq \alpha\|B x-B y\|^{2}, \quad \forall x, y \in C .
$$

If an operator $B$ is an $\alpha$-inverse-strongly monotone, then we can said that $B$ is Lipschitz continuous; that is, $\|B x-B y\| \leq(1 / \alpha)\|x-y\|$ for all $x, y \in C$.

Let $f: C \times C \rightarrow \mathbb{R}$ be a bifunction, $\varphi: C \rightarrow \mathbb{R}$ a real-valued function, and $B: C \rightarrow E^{*}$ be a nonlinear mapping. The generalized mixed equilibrium problem is to find $x \in C$ such that

$$
f(x, y)+\langle B x, y-x\rangle+\varphi(y)-\varphi(x) \geq 0, \quad \forall y \in C .
$$

We denote $\Omega$ as the set of solutions to (1.2) that is,

$$
\Omega=\{x \in C: f(x, y)+\langle B x, y-x\rangle+\varphi(y)-\varphi(x) \geq 0, \forall y \in C\}
$$

If $B \equiv 0$, the problem (1.2) reduced into the mixed equilibrium problem for $f$, denoted by $\operatorname{MEP}(f, \varphi)$, is to find $x \in C$ such that

$$
f(x, y)+\varphi(y)-\varphi(x) \geq 0, \quad \forall y \in C
$$

If $f \equiv 0$, the problem (1.2) reduced into the mixed variational inequality of Browder type, denoted by $\operatorname{VI}(C, B, \varphi)$, is to find $x \in C$ such that

$$
\langle B x, y-x\rangle+\varphi(y)-\varphi(x) \geq 0, \quad \forall y \in C
$$


If $B \equiv 0$ and $\varphi \equiv 0$ the problem (1.2), reduced into the equilibrium problem for $F$, denoted by $\operatorname{EP}(f)$, is to find $x \in C$ such that

$$
f(x, y) \geq 0, \quad \forall y \in C
$$

In addition, fixed point problem, optimization problem, and many problems can be written in the form of $\operatorname{EP}(f)$. There are the development of researches in this area as seen in many papers which appeared in the literature on the existence of the solutions of $\operatorname{EP}(f)$; see, for example [17-21] and reference therein. Furthermore, there are many solution methods proposed continuously to solve the $\operatorname{EP}(f)$ as shown in $[2,3,18,20,22-26]$ and many others.

Next, we let $B$ be a monotone operator of $C$ into $E^{*}$. The so-called variational inequality problem is to find a point $x \in C$ such that

$$
\langle B x, y-x\rangle \geq 0 \quad \forall y \in C
$$

The set of solutions of the variational inequality problem is denoted by $\operatorname{VI}(C, B)$.

As we know that the classical variational inequality was first introduced and studied by Stampacchia [27] in 1964. Its solution can be computed by using iterative projection method. There are many results with corresponding to variational inequality; for example, Yao et al. [28] proposed the strong convergence theorem for a system of nonlinear variational inequalities in Banach spaces, and then, they studied the two-step projection methods, and they established the convergence theorem for a system of variational inequality problems in the framework of Banach spaces. Moreover, the important generalized variational inequalities called variational inclusion also have been extensively studied and extended in many different directions. Yao et al. [29] considered the algorithm and proved the strong convergence of common solutions for variational inclusions, mixed equilibrium problems, and fixed point problems.

The one classical way to approximate a fixed point of a nonlinear self mapping $T$ on $C$ was firstly introduced by Halpern [30], and then, Aoyama et al. [31] extended the mapping in the Halpern-type iterative sequence to be a countable family of nonexpansive mappings. They introduced the following iterative sequence: let $x_{1}=x \in C$ and

$$
x_{n+1}=\alpha_{n} x+\left(1-\alpha_{n}\right) T_{n} x_{n}
$$

for all $n \in \mathbb{N}$, where $C$ is a nonempty closed convex subset of a Banach space, $\left\{\alpha_{n}\right\}$ is a sequence in $[0,1]$, and $\left\{T_{n}\right\}$ is a sequence of nonexpansive mappings with some conditions. They proved that $\left\{x_{n}\right\}$ converges strongly to a common fixed point of $\left\{T_{n}\right\}$.

Recently, Nakajo et al. [32] introduced the more general condition so-called the NST*condition, and $\left\{T_{n}\right\}$ is said to satisfy the NST*-condition if for every bounded sequence $\left\{z_{n}\right\}$ in $C$,

$$
\lim _{n \rightarrow \infty}\left\|z_{n}-T_{n} z_{n}\right\|=\lim _{n \rightarrow \infty}\left\|z_{n}-z_{n+1}\right\|=0 \quad \text { implies } \quad \omega_{w}\left(z_{n}\right) \subset F .
$$

They also prove strong convergence theorems by the hybrid method for families of mappings in a uniformly convex Banach space $E$ whose norm is Gâteaux differentiable. 
In Hilbert space $H$, Iiduka et al. [33] introduced an iterative scheme and proved that the sequence $\left\{x_{n}\right\}$ generated by the following algorithm: $x_{1}=x \in C$, and

$$
x_{n+1}=P_{C}\left(x_{n}-\lambda_{n} B x_{n}\right),
$$

where $P_{C}$ is the metric projection of $H$ onto $C$ and $\left\{\lambda_{n}\right\}$ is a sequence of positive real numbers, converges weakly to some element of $\mathrm{VI}(C, B)$.

Later, Iiduka and Takahashi [34] are interested in the similar problem in the framework of Banach spaces, they introduced the following iterative scheme for finding a solution of the variational inequality problem for an inverse-strongly monotone operator $B: x_{1}=x \in C$, and

$$
x_{n+1}=\Pi_{C} J^{-1}\left(J x_{n}-\lambda_{n} B x_{n}\right)
$$

for every $n=1,2,3, \ldots$, where $\Pi_{C}$ is the generalized metric projection from $E$ onto $C, J$ is the duality mapping from $E$ into $E^{*}$, and $\left\{\lambda_{n}\right\}$ is a sequence of positive real numbers. They proved that the sequence $\left\{x_{n}\right\}$ generated by (1.11) converges weakly to some element of $\operatorname{VI}(C, B)$.

In 1974, Rockafellar interested in the following problem of finding:

$$
v \in E \text { such that } 0 \in A(v) \text {, }
$$

where $A$ is an operator from $E$ into $E^{*}$. Such $v \in E$ is called a zero point of $A$. He introduced a well-known method, proximal point algorithm, for solving (1.12) in a Hilbert space $H$ as shown in the following: $x_{1}=x \in H$ and

$$
x_{n+1}=J_{r_{n}} x_{n}, \quad n=1,2,3, \ldots,
$$

where $\left\{r_{n}\right\} \subset(0, \infty), A$ is a maximal monotone and $J_{r_{n}}=\left(I+r_{n} A\right)^{-1}$. He proved that the sequence $\left\{x_{n}\right\}$ converges weakly to an element of $A^{-1}(0)$.

In 2004, Kamimura et al. [35] considered the algorithm (1.14) in a uniformly smooth and uniformly convex Banach space $E$; namely,

$$
x_{n+1}=J^{-1}\left(\alpha_{n} J x_{n}+\left(1-\alpha_{n}\right) J\left(J_{r_{n}} x_{n}\right)\right), \quad n=1,2,3, \ldots
$$

They proved that the algorithm $\left\{x_{n}\right\}$ generated by (1.14) converges weakly to some element of $A^{-1} 0$.

In 2008, Li and Song [36] established a strong convergence theorem in a Banach space. They introduced the following algorithm: $x_{1}=x \in E$ and

$$
\begin{gathered}
y_{n}=J^{-1}\left(\beta_{n} J\left(x_{n}\right)+\left(1-\beta_{n}\right) J\left(J_{r_{n}} x_{n}\right)\right), \\
x_{n+1}=J^{-1}\left(\alpha_{n} J x+\left(1-\alpha_{n}\right) J\left(y_{n}\right)\right) .
\end{gathered}
$$

Under the suitable conditions of the coefficient sequences $\left\{\alpha_{n}\right\},\left\{\beta_{n}\right\}$, and $\left\{r_{n}\right\}$, they proved that the sequence $\left\{x_{n}\right\}$ generated by the above scheme converges strongly to $\Pi_{C} x$, where $\Pi_{C}$ is the generalized projection from $E$ onto $C$. 
In 2010, Petrot et al. [37] introduced a hybrid projection iterative scheme for approximating a common element of the set of solutions of a generalized mixed equilibrium problem and the set of fixed points of two quasi- $\phi$-nonexpansive mappings in a real uniformly convex and uniformly smooth Banach space by the following manner:

$$
\begin{aligned}
x_{0} & =x \in C, \\
y_{n} & =J^{-1}\left(\delta_{n} J x_{n}+\left(1-\delta_{n}\right) J z_{n}\right), \\
z_{n} & =J^{-1}\left(\alpha_{n} J x_{n}+\beta_{n} J T x_{n}+\gamma_{n} J S x_{n}\right), \\
u_{n} & =K_{r_{n}} y_{n}, \\
C_{n} & =\left\{z \in C: \phi\left(z, u_{n}\right) \leq \phi\left(z, x_{n}\right)\right\}, \\
Q_{n} & =\left\{z \in C:\left\langle x_{n}-z, J x-J x_{n}\right\rangle \geq 0\right\}, \\
x_{n+1} & =\prod_{C_{n} \cap Q_{n}} x .
\end{aligned}
$$

They proved that $\left\{x_{n}\right\}$ converges strongly to $p \in F(T) \cap F(S) \cap \Omega$, where $p \in \Pi_{F(T) \cap F(S) \cap \Omega} x$.

Recently, Klin-eam et al. [38], obtained the strong convergence theorem for finding a common element of the zero point set of a maximal monotone operator and the fixed point set of two relatively nonexpansive mappings in a Banach space by using a new hybrid method. Saewan and Kumam [39] introduced a new hybrid projection method for finding a common solution of the set of common fixed points of two countable families of relatively quasi-nonexpansive mappings, the set of the variational inequality for an $\alpha$-inverse-strongly monotone operator, the set of solutions of the generalized mixed equilibrium problem, and zeros of a maximal monotone operator in a real uniformly smooth and 2-uniformly convex Banach space. Wattanawitoon and Kumam [40] proved the strong convergence theorem by using modified hybrid projection method for finding a common element of the set of solutions of generalized mixed equilibrium problems, the set of solution of variational inequality operators of an inverse strongly monotone, the zero point of a maximal monotone operator, and the set of fixed point of two relatively quasi-nonexpansive mappings in Banach space.

Motivated and inspired by the ongoing research and the above-mentioned results, we are also interested in generalized mixed equilibrium problem, variational inequality problems, and the zero point of maximal monotone operators. In this paper, we extend the fixed point problems of two relatively quasi-nonexpansive mappings in [40] to the countable families of two quasi- $\phi$-nonexpansive mappings and improve the iterative scheme to be more general as shown in the following: $x_{1}=x \in C$,

$$
\begin{aligned}
& w_{n}=\Pi_{C} J^{-1}\left(J x_{n}-\lambda_{n} B x_{n}\right), \\
& z_{n}=J^{-1}\left(\delta_{n} J\left(x_{n}\right)+\left(1-\delta_{n}\right) J\left(J_{r_{n}} w_{n}\right)\right), \\
& y_{n}=J^{-1}\left(\alpha_{n} J x_{n}+\beta_{n} J T_{n} x_{n}+\gamma_{n} J S_{n} z_{n}\right), \\
& u_{n} \in C \text { such that } F\left(u_{n}, y\right)+\left\langle Y u_{n}, y-u_{n}\right\rangle+\varphi(y)-\varphi\left(u_{n}\right) \\
& \qquad+\frac{1}{r_{n}}\left\langle y-u_{n}, J u_{n}-J y_{n}\right\rangle \geq 0, \quad \forall y \in C,
\end{aligned}
$$




$$
\begin{aligned}
& C_{n+1}=\left\{z \in C: \phi\left(z, u_{n}\right) \leq \phi\left(z, x_{n}\right)\right\}, \\
& x_{n+1}=\prod_{C_{n+1}} x .
\end{aligned}
$$

By the new iterative scheme, we will prove the strong convergence theorems of the sequence $\left\{x_{n}\right\}$ which could be converged to the point $\prod_{\left(\cap_{n=1}^{\infty} F\left(T_{n}\right)\right) \cap\left(\cap_{n=1}^{\infty} F\left(S_{n}\right)\right) \cap \Omega \cap V I(C, B) \cap A^{-1}(0)} x$. Furthermore, we propose the new better appropriate conditions of the coefficient sequences $\left\{\alpha_{n}\right\},\left\{\beta_{n}\right\},\left\{\gamma_{n}\right\}$, and $\left\{r_{n}\right\}$. Finally, we will apply our result to find a zero point of inversestrongly monotone operators and complementarity problem in the last section. The results presented in this paper extend and improve the corresponding ones announced by Kamimura et al. [35], Petrot et al. [37], Wattanawitoon and Kumam [40], and some authors in the literature.

\section{Preliminaries}

In this section, we propose the following preliminaries and lemmas which will be used in our proof.

Throughout this paper, we let $E$ be a Banach space with norm $\|\cdot\|$, and $C$ a nonempty closed convex subset of $E$, and let $E^{*}$ denote the dual of $E$. We write $x_{n} \rightarrow x$ to indicate that the sequence $\left\{x_{n}\right\}$ converges weakly to $x$ and $x_{n} \rightarrow x$ implies that the sequence $\left\{x_{n}\right\}$ converges strongly to $x$.

Let $U=\{x \in E:\|x\|=1\}$ be the unit sphere of $E$. A Banach space $E$ is said to be strictly convex if for any $x, y \in U$,

$$
x \neq y \quad \text { implies } \quad\left\|\frac{x+y}{2}\right\|<1
$$

It is also said to be uniformly convex if for each $\epsilon \in(0,2]$, there exists $\delta>0$ such that for any $x, y \in U$

$$
\|x-y\| \geq \epsilon \quad \text { implies } \quad\left\|\frac{x+y}{2}\right\|<1-\delta .
$$

We know that a uniformly convex Banach space is reflexive and strictly convex; see [41, 42] for more details.

The modulus of convexity of $E$ is the function $\delta:[0,2] \rightarrow[0,1]$ defined by

$$
\delta(\varepsilon)=\inf \left\{1-\left\|\frac{x+y}{2}\right\|: x, y \in E,\|x\|=\|y\|=1,\|x-y\| \geq \varepsilon\right\} .
$$

Furthermore, it is said to be smooth, provided that

$$
\lim _{t \rightarrow 0} \frac{\|x+t y\|-\|x\|}{t}
$$

exists for all $x, y \in U$. It is also said to be uniformly smooth if the limit is attained uniformly for $x, y \in E$. 
Let $p$ be a fixed real number with $p \geq 2$. Observe that every $p$-uniformly convex is uniformly convex. One should note that no a Banach space is $p$-uniformly convex for $1<p<$ 2. It is well known that a Hilbert space is 2-uniformly convex and uniformly smooth. For each $p>1$, the generalized duality mapping $J_{p}: E \rightarrow 2^{E^{*}}$ is defined by

$$
J_{p}(x)=\left\{x^{*} \in E^{*}:\left\langle x, x^{*}\right\rangle=\|x\|^{p},\left\|x^{*}\right\|=\|x\|^{p-1}\right\},
$$

for all $x \in E$.

In particular, $J=J_{2}$ is called the normalized duality mapping. If $E$ is a Hilbert space, then $J=I$, where $I$ is the identity mapping. It is also known that if $E$ is uniformly smooth, then $J$ is uniformly norm-to-norm continuous on each bounded subset of $E$.

We know the following (see [43]):

(1) if $E$ is smooth, then $J$ is single-valued,

(2) if $E$ is strictly convex, then $J$ is one-to-one and $\left\langle x-y, x^{*}-y^{*}\right\rangle>0$ holds for all $\left(x, x^{*}\right),\left(y, y^{*}\right) \in J$ with $x \neq y$,

(3) if $E$ is reflexive, then $J$ is surjective,

(4) if $E$ is uniformly convex, then it is reflexive,

(5) if $E^{*}$ is uniformly convex, then $J$ is uniformly norm-to-norm continuous on each bounded subset of $E$.

The duality $J$ from a smooth Banach space $E$ into $E^{*}$ is said to be weakly sequentially continuous [44] if $x_{n} \rightarrow x$ implies $J x_{n}-^{*} J x$, where $-^{*}$ implies the weak* convergence.

Let $E$ be a smooth, strictly convex and reflexive Banach space, and let $C$ be a nonempty closed convex subset of $E$. Throughout this paper, we denote by $\phi$ the function defined by

$$
\phi(x, y)=\|x\|^{2}-2\langle x, J y\rangle+\|y\|^{2}, \quad \text { for } x, y \in E .
$$

Remark 2.1. We know the following: for each $x, y, z \in E$,

(i) $(\|x\|-\|y\|)^{2} \leq \phi(x, y) \leq(\|x\|+\|y\|)^{2}$,

(ii) $\phi(x, y)=\phi(x, z)+\phi(z, y)+2\langle x-z, J z-J y\rangle$,

(iii) $\phi(x, y)=\|x-y\|^{2}$ in a real Hilbert space.

The generalized projection, introduced by Alber [45], $\Pi_{C}: E \rightarrow C$ is a map that assigns to an arbitrary point $x \in E$ the minimum point of the function $\phi(x, y)$; that is, $\Pi_{C} x=\bar{x}$, where $\bar{x}$ is the solution to the minimization problem

$$
\phi(\bar{x}, x)=\inf _{y \in C} \phi(y, x),
$$

existence and uniqueness of the operator $\Pi_{C}$ follows from the properties of the functional $\phi(x, y)$ and strict monotonicity of the mapping $J$.

If $E$ is a reflexive, strictly convex and smooth Banach space, then for $x, y \in E, \phi(x, y)=$ 0 , if and only if $x=y$. It is sufficient to show that if $\phi(x, y)=0$, then $x=y$. From Remark 2.1 (i), we have $\|x\|=\|y\|$. This implies that $\langle x, J y\rangle=\|x\|^{2}=\|J y\|^{2}$. From the definition of $J$, one has $J x=J y$. Therefore, we have $x=y$; see $[43,46]$ for more details. 
Lemma 2.2 (see $[47,48]$ ). If E be a 2-uniformly convex Banach space, then for all $x, y \in E$, one has

$$
\|x-y\| \leq \frac{2}{c^{2}}\|J x-J y\|
$$

where $J$ is the normalized duality mapping of $E$ and $0<c \leq 1$. [41].

The best constant $1 / c$ in the Lemma is called the 2-uniformly convex constant of $E$; see

Lemma 2.3 (see $[47,49])$. If $E$ is a $p$-uniformly convex Banach space and $p$ a given real number with $p \geq 2$, then for all $x, y \in E, J_{x} \in J_{p}(x)$ and $J_{y} \in J_{p}(y)$

$$
\langle x-y, J x-J y\rangle \geq \frac{c^{p}}{2^{p-2} p}\|x-y\|^{p}
$$

where $J_{p}$ is the generalized duality mapping of $E$ and $1 / c$ is the $p$-uniformly convexity constant of $E$.

Lemma 2.4 (Xu [48]). Let E be a uniformly convex Banach space, then for each $r>0$, there exists a strictly increasing, continuous and convex function $g:[0, \infty) \rightarrow[0, \infty)$ such that $g(0)=0$ and

$$
\|\lambda x+(1-\lambda y)\|^{2} \leq \lambda\|x\|^{2}+(1-\lambda)\|y\|^{2}-\lambda(1-\lambda) g(\|x-y\|)
$$

for all $x, y \in\{z \in E:\|z\| \leq r\}$ and $\lambda \in[0,1]$.

Lemma 2.5 (Kamimura and Takahashi [50]). Let E be a uniformly convex and smooth real Banach space and $\left\{x_{n}\right\},\left\{y_{n}\right\}$ two sequences of $E$. If $\phi\left(x_{n}, y_{n}\right) \rightarrow 0$ and either $\left\{x_{n}\right\}$ or $\left\{y_{n}\right\}$ is bounded, then $\left\|x_{n}-y_{n}\right\| \rightarrow 0$.

Lemma 2.6 (Alber [45]). Let $C$ be a nonempty closed convex subset of a smooth Banach space $E$ and $x \in E$. Then, $x_{0}=\Pi_{C} x$ if and only if

$$
\left\langle x_{0}-y, J x-J x_{0}\right\rangle \geq 0, \quad \forall y \in C .
$$

Lemma 2.7 (Alber [45]). Let E be a reflexive, strictly convex and smooth Banach space and $C$ a nonempty closed convex subset of $E$ and let $x \in E$. Then,

$$
\phi\left(y, \Pi_{C} x\right)+\phi\left(\Pi_{C} x, x\right) \leq \phi(y, x), \quad \forall y \in C
$$

Let $E$ be a strictly convex, smooth, and reflexive Banach space and $J$ the duality mapping from $E$ into $E^{*}$. Then, $J^{-1}$ is also single-valued, one-to-one, and surjective, and it is the duality mapping from $E^{*}$ into $E$. Define a function $V: E \times E^{*} \rightarrow \mathbb{R}$ as follows (see [51]):

$$
V\left(x, x^{*}\right)=\|x\|^{2}-2\left\langle x, x^{*}\right\rangle+\left\|x^{*}\right\|^{2}
$$

for all $x \in E$ and $x^{*} \in E^{*}$. Then, it is obvious that $V\left(x, x^{*}\right)=\phi\left(x, J^{-1}\left(x^{*}\right)\right)$ and $V(x, J(y))=$ $\phi(x, y)$. 
Lemma 2.8 (Kohsaka and Takahashi [51, Lemma 3.2]). Let E be a strictly convex, smooth, and reflexive Banach space and $V$ as in (2.13). Then,

$$
V\left(x, x^{*}\right)+2\left\langle J^{-1}\left(x^{*}\right)-x, y^{*}\right\rangle \leq V\left(x, x^{*}+y^{*}\right)
$$

for all $x \in E$ and $x^{*}, y^{*} \in E^{*}$.

For solving the generalized mixed equilibrium problem, let us assume that the bifunction $F: C \times C \rightarrow \mathbb{R}$ and $\varphi: C \rightarrow \mathbb{R}$ is convex and lower semicontinuous, satisfying the following conditions:

(A1) $F(x, x)=0$ for all $x \in C$,

(A2) $F$ is monotone, that is, $F(x, y)+F(y, x) \leq 0$ for all $x, y \in C$,

(A3) for each $x, y, z \in C$,

$$
\limsup _{t \downarrow 0} F(t z+(1-t) x, y) \leq F(x, y)
$$

(A4) for each $x \in C, y \mapsto F(x, y)$ is convex and lower semicontinuous.

Lemma 2.9 (Blum and Oettli [17]). Let $C$ be a closed convex subset of a uniformly smooth, strictly convex, and reflexive Banach space $E$ and $F$ a bifunction of $C \times C$ into $\mathbb{R}$ satisfying (A1)-(A4). Let $r>0$ and $x \in E$. Then, there exists $z \in C$ such that

$$
F(z, y)+\frac{1}{r}\langle y-z, z-x\rangle \geq 0 \quad \forall y \in C
$$

Lemma 2.10 (Takahashi and Zembayashi [52]). Let $C$ be a closed convex subset of a uniformly smooth, strictly convex, and reflexive Banach space $E$ and $F$ a bifunction from $C \times C$ to $\mathbb{R}$ satisfying (A1)-(A4). For all $r>0$ and $x \in E$, define a mapping $T_{r}: E \rightarrow C$ as follows:

$$
T_{r} x=\left\{z \in C: F(z, y)+\frac{1}{r}\langle y-z, J z-J x\rangle \geq 0, \forall y \in C\right\}
$$

for all $x \in E$. Then, the following hold:

(1) $T_{r}$ is single-valued,

(2) $T_{r}$ is a firmly nonexpansive-type mapping, that is, for all $x, y \in E$,

$$
\left\langle T_{r} x-T_{r} y, J T_{r} x-J T_{r} y\right\rangle \leq\left\langle T_{r} x-T_{r} y, J x-J y\right\rangle,
$$

(3) $F\left(T_{r}\right)=E P(F)$,

(4) $E P(F)$ is closed and convex. 
Lemma 2.11 (Takahashi and Zembayashi [52]). Let $C$ be a closed convex subset of a smooth, strictly convex, and reflexive Banach space $E$, and $F$ a bifunction from $C \times C$ to $\mathbb{R}$ satisfying (A1)-(A4) and let $r>0$. Then, for $x \in E$ and $q \in F\left(T_{r}\right)$,

$$
\phi\left(q, T_{r} x\right)+\phi\left(T_{r} x, x\right) \leq \phi(q, x) .
$$

Lemma 2.12 (Zhang [53]). Let $C$ be a closed convex subset of a smooth, strictly convex, and reflexive Banach space $E$. Let $B: C \rightarrow E^{*}$ be a continuous and monotone mapping, $\varphi: C \rightarrow \mathbb{R}$ convex and lower semi-continuous, and $F$ a bifunction from $C \times C$ to $\mathbb{R}$ satisfying $(A 1)-(A 4)$. For $r>0$ and $x \in E$, then there exists $u \in C$ such that

$$
F(u, y)+\langle B u, y-u\rangle+\varphi(y)-\varphi(u)+\frac{1}{r}\langle y-u, J u-J x\rangle \geq 0, \quad \forall y \in C .
$$

Define a mapping $K_{r}: C \rightarrow C$ as follows:

$$
K_{r}(x)=\left\{u \in C: F(u, y)+\langle B u, y-u\rangle+\varphi(y)-\varphi(u)+\frac{1}{r}\langle y-u, J u-J x\rangle \geq 0, \forall y \in C\right\},
$$

for all $x \in E$. Then, the following hold:

(i) $K_{r}$ is single-valued,

(ii) $K_{r}$ is firmly nonexpansive, that is, for all $x, y \in E,\left\langle K_{r} x-K_{r} y, J K_{r} x-J K_{r} y\right\rangle \leq\left\langle K_{r} x-\right.$ $\left.K_{r} y, J x-J y\right\rangle$,

(iii) $F\left(K_{r}\right)=\Omega$,

(iv) $\Omega$ is closed and convex,

(v) $\phi\left(p, K_{r} z\right)+\phi\left(K_{r} z, z\right) \leq \phi(p, z)$ for all $p \in F\left(K_{r}\right), z \in E$.

It follows from Lemma 2.10 that the mapping $K_{r}: C \rightarrow C$ defined by (2.21) is a relatively nonexpansive mapping. Thus, it is quasi- $\phi$-nonexpansive.

Let $E$ be a reflexive, strictly convex and smooth Banach space. Let $C$ be a closed convex subset of $E$. Because $\phi(x, y)$ is strictly convex and coercive in the first variable, we know that the minimization problem $\inf _{y \in C} \phi(x, y)$ has a unique solution. The operator $\Pi_{C} x:=\arg \min _{y \in C} \phi(x, y)$ is said to be the generalized projection of $x$ on $C$.

Let $A$ be a set-valued mapping from $E$ to $E^{*}$ with graph $G(A)=\left\{\left(x, x^{*}\right): x^{*} \in A x\right\}$, domain $D(A)=\{x \in E: A(x) \neq \emptyset\}$, and range $R(A)=\left\{x^{*} \in E^{*}: x^{*} \in A(x), x \in D(A)\right\}$. We denote a set-valued operator $A$ from $E$ to $E^{*}$ by $A \subset E \times E^{*}$. $A$ is said to be monotone if $\left\langle x-y, x^{*}-y^{*}\right\rangle \geq 0$ for all $\left(x, x^{*}\right),\left(y, y^{*}\right) \in A$. A monotone operator $A \subset E \times E^{*}$ is said to be maximal monotone if it graph is not properly contained in the graph of any other monotone operator. We know that if $A$ is maximal monotone, then the solution set $A^{-1} 0=\{z \in D(A)$ : $0 \in A z\}$ is closed and convex.

Let $E$ be a reflexive, strictly convex and smooth Banach space, it is known that $A$ is maximal monotone if and only if $R(J+r A)=E^{*}$ for all $r>0$.

Define the resolvent of $A$ by $J_{r} x=x_{r}$. In other words, $J_{r}=(J+r A)^{-1} J$ for all $r>0 . J_{r}$ is a single-valued mapping from $E$ to $D(A)$. Also, $A^{-1}(0)=F\left(J_{r}\right)$ for all $r>0$, where $F\left(J_{r}\right)$ is the 
set of all fixed points of $J_{r}$. Define, for $r>0$, the Yosida approximation of $A$ by $A_{r}=\left(J-J J_{r}\right) / r$. We know that $A_{r} x \in A\left(J_{r} x\right)$ for all $r>0$ and $x \in E$.

Lemma 2.13 (Kohsaka and Takahashi [51, Lemma 3.1]). Let E be a smooth, strictly convex, and reflexive Banach space, let $A \subset E \times E^{*}$ be a maximal monotone operator with $A^{-1} 0 \neq \emptyset, r>0$, and $J_{r}=(J+r T)^{-1} J$. Then,

$$
\phi\left(x, J_{r} y\right)+\phi\left(J_{r} y, y\right) \leq \phi(x, y)
$$

for all $x \in A^{-1} 0$ and $y \in E$.

Let $B$ be an inverse-strongly monotone mapping of $C$ into $E^{*}$ which is said to be hemicontinuous if for all $x, y \in C$, the mapping $F$ of $[0,1]$ into $E^{*}$, defined by $F(t)=$ $B(t x+(1-t) y)$, is continuous with respect to the weak topology of $E^{*}$. We define by $N_{C}(v)$ the normal cone for $C$ at a point $v \in C$; that is,

$$
N_{C}(v)=\left\{x^{*} \in E^{*}:\left\langle v-y, x^{*}\right\rangle \geq 0, \forall y \in C\right\} .
$$

Theorem 2.14. (Rockafellar [54]). Let $C$ be a nonempty, closed convex subset of a Banach space $E$ and $B$ a monotone, hemicontinuous operator of $C$ into $E^{*}$. Let $T \subset E \times E^{*}$ be an operator defined as follows:

$$
T v=\left\{\begin{array}{lc}
B v+N_{C}(v), & v \in C \\
\emptyset, & \text { otherwise }
\end{array}\right.
$$

Then $T$, is maximal monotone and $T^{-1} 0=\mathrm{VI}(C, B)$.

Lemma 2.15 (Tan and $\mathrm{Xu}[55]$ ). Let $\left\{a_{n}\right\}$ and $\left\{b_{n}\right\}$ be two sequences of nonnegative real numbers satisfying

$$
a_{n+1} \leq a_{n}+b_{n}, \quad \forall n \geq 0 .
$$

If $\sum_{n=1}^{\infty} b_{n}<\infty$, then $\lim _{n \rightarrow \infty} a_{n}$ exists.

\section{The Main Result}

In this section, we prove a strong convergence theorem for finding a common element of the set of solutions of mixed equilibrium problems, the set of solutions of the variational inequality problem, the zero point of a maximal monotone operator, and the set of two families of quasi- $\phi$-nonexpansive mappings in a Banach space by using the shrinking hybrid projection method.

Theorem 3.1. Let $E$ be a 2-uniformly convex and uniformly smooth Banach space and $C$ a nonempty closed convex subset of $E$. Let $F$ be a bifunction from $C \times C$ to $\mathbb{R}$ satisfying $(A 1)-(A 4)$, let $\varphi: C \rightarrow \mathbb{R}$ be a proper lower semicontinuous and convex function, and let $A: E \rightarrow E^{*}$ be a maximal monotone operator satisfying $D(A) \subset E$. Let $J_{r}=(J+r A)^{-1} J$ for $r>0$, let $B$ be an $\alpha$-inverse-strongly monotone 
operator of $E$ into $E^{*}$, and let $Y: E \rightarrow E^{*}$ be a continuous and monotone mapping. Let $\left\{T_{n}\right\}$ and $\left\{S_{n}\right\}$ be two families of quasi- $\phi$-nonexpansive mappings of $E$ into itself satisfies the NST ${ }^{*}$-condition, with $\Theta:=\left(\cap_{n=1}^{\infty} F\left(T_{n}\right)\right) \cap\left(\cap_{n=1}^{\infty} F\left(S_{n}\right)\right) \cap \Omega \cap V I(C, B) \cap A^{-1}(0) \neq \emptyset$ and $\|B y\| \leq\|B y-B u\|$ for all $y \in C$ and $u \in \Theta$. Let $\left\{x_{n}\right\}$ be a sequence generated by $x_{1}=x \in E$, and

$$
\begin{aligned}
w_{n} & =\Pi_{C} J^{-1}\left(J x_{n}-\lambda_{n} B x_{n}\right), \\
z_{n} & =J^{-1}\left(\delta_{n} J\left(x_{n}\right)+\left(1-\delta_{n}\right) J\left(J_{r_{n}} w_{n}\right)\right), \\
y_{n} & =J^{-1}\left(\alpha_{n} J x_{n}+\beta_{n} J T_{n} x_{n}+\gamma_{n} J S_{n} z_{n}\right), \\
u_{n} & \in C \text { such that } F\left(u_{n}, y\right)+\left\langle Y u_{n}, y-u_{n}\right\rangle+\varphi(y)-\varphi\left(u_{n}\right) \\
C_{n+1} & =\left\{z \in C: \phi\left(z, u_{n}\right) \leq \phi\left(z, x_{n}\right)\right\}, \\
x_{n+1} & =\Pi_{C_{n+1}} x,
\end{aligned}
$$

for all $n \in \mathbb{N}$. If the coefficient sequence $\left\{\alpha_{n}\right\},\left\{\beta_{n}\right\},\left\{\gamma_{n}\right\}$, and $\left\{\delta_{n}\right\} \subset[0,1],\left\{r_{n}\right\} \subset(0, \infty)$ satisfy $\alpha_{n}+$ $\beta_{n}+\gamma_{n}=1, \liminf _{n \rightarrow \infty} \alpha_{n} \beta_{n}>0, \liminf _{n \rightarrow \infty} \alpha_{n} \gamma_{n}>0, \liminf _{n \rightarrow \infty} \gamma_{n}\left(1-\delta_{n}\right)>0, \liminf _{n \rightarrow \infty} r_{n}>0$ and $\left\{\lambda_{n}\right\} \subset[a, b]$ for some $a, b$ with $0<a<b<c^{2} \alpha / 2,1 / c$ is the 2-uniformly convexity constant of $E$. Then the sequence $\left\{x_{n}\right\}$ converges strongly to $\Pi_{\Theta} x$.

Proof. We first show that $\left\{x_{n}\right\}$ is bounded. Let $p \in \Theta:=\left(\cap_{n=1}^{\infty} F\left(T_{n}\right)\right) \cap\left(\cap_{n=1}^{\infty} F\left(S_{n}\right)\right) \cap \Omega \cap$ $\mathrm{VI}(C, B) \cap A^{-1}(0)$, and let

$$
\begin{aligned}
& H\left(u_{n}, y\right)=F\left(u_{n}, y\right)+\left\langle Y u_{n}, y-u_{n}\right\rangle+\varphi(y)-\varphi\left(u_{n}\right), \quad y \in C, \\
& K_{r_{n}}=\left\{u \in C: H\left(u_{n}, y\right)+\frac{1}{r_{n}}\left\langle y-u_{n}, J u_{n}-J y_{n}\right\rangle \geq 0, \forall y \in C\right\} .
\end{aligned}
$$

Put $v_{n}=J^{-1}\left(J x_{n}-\lambda_{n} B x_{n}\right)$ and $u_{n}=K_{r_{n}} y_{n}$.

With its relatively nonexpansiveness of $J_{r_{n}}$ and by Lemma 2.8 , the convexity of the function $V$ in the second variable, we have

$$
\begin{aligned}
\phi\left(p, w_{n}\right) & =\phi\left(p, \Pi_{C} v_{n}\right) \\
& \leq \phi\left(p, v_{n}\right)=\phi\left(p, J^{-1}\left(J x_{n}-\lambda_{n} B x_{n}\right)\right) \\
& \leq V\left(p, J x_{n}-\lambda_{n} B x_{n}+\lambda_{n} B x_{n}\right)-2\left\langle J^{-1}\left(J x_{n}-\lambda_{n} B x_{n}\right)-p, \lambda_{n} B x_{n}\right\rangle \\
& =V\left(p, J x_{n}\right)-2 \lambda_{n}\left\langle v_{n}-p, B x_{n}\right\rangle \\
& =\phi\left(p, x_{n}\right)-2 \lambda_{n}\left\langle x_{n}-p, B x_{n}\right\rangle+2\left\langle v_{n}-x_{n},-\lambda_{n} B x_{n}\right\rangle .
\end{aligned}
$$


Journal of Applied Mathematics

Since $p \in \operatorname{VI}(C, B)$ and $B$ is $\alpha$-inverse-strongly monotone, we consider

$$
\begin{aligned}
-2 \lambda_{n}\left\langle x_{n}-p, B x_{n}\right\rangle & =-2 \lambda_{n}\left\langle x_{n}-p, B x_{n}-B p\right\rangle-2 \lambda_{n}\left\langle x_{n}-p, B p\right\rangle \\
& \leq-2 \alpha \lambda_{n}\left\|B x_{n}-B p\right\|^{2} .
\end{aligned}
$$

Therefore, by Lemma 2.2, we obtain

$$
\begin{aligned}
2\left\langle v_{n}-x_{n},-\lambda_{n} B x_{n}\right\rangle & =2\left\langle J^{-1}\left(J x_{n}-\lambda_{n} B x_{n}\right)-J^{-1}\left(J x_{n}\right),-\lambda_{n} B x_{n}\right\rangle \\
& \leq 2\left\|J^{-1}\left(J x_{n}-\lambda_{n} B x_{n}\right)-J^{-1}\left(J x_{n}\right)\right\|\left\|\lambda_{n} B x_{n}\right\| \\
& \leq \frac{4}{c^{2}}\left\|J x_{n}-\lambda_{n} B x_{n}-J x_{n}\right\|\left\|\lambda_{n} B x_{n}\right\| \\
& =\frac{4}{c^{2}} \lambda_{n}^{2}\left\|B x_{n}\right\|^{2} \\
& \leq \frac{4}{c^{2}} \lambda_{n}^{2}\left\|B x_{n}-B p\right\|^{2} .
\end{aligned}
$$

We can rewrite (3.3), which yield that

$$
\begin{aligned}
\phi\left(p, w_{n}\right) & \leq \phi\left(p, x_{n}\right)-2 \alpha \lambda_{n}\left\|B x_{n}-B p\right\|^{2}+\frac{4}{c^{2}} \lambda_{n}^{2}\left\|B x_{n}-B p\right\|^{2} \\
& \leq \phi\left(p, x_{n}\right)+2 \lambda_{n}\left(\frac{2}{c^{2}} \lambda_{n}-\alpha\right)\left\|B x_{n}-B p\right\|^{2} \\
& \leq \phi\left(p, x_{n}\right) .
\end{aligned}
$$

Apply the Lemma 2.8, Lemma 2.13 and (3.6), we consider

$$
\begin{aligned}
\phi\left(p, z_{n}\right) & =\phi\left(p, J^{-1}\left(\delta_{n} J\left(x_{n}\right)+\left(1-\delta_{n}\right) J\left(J_{r_{n}} w_{n}\right)\right)\right) \\
& =V\left(p, \delta_{n} J\left(x_{n}\right)+\left(1-\delta_{n}\right) J\left(J_{r_{n}} w_{n}\right)\right) \\
& \leq \delta_{n} V\left(p, J\left(x_{n}\right)\right)+\left(1-\delta_{n}\right) V\left(p, J\left(J_{r_{n}} w_{n}\right)\right) \\
& =\delta_{n} \phi\left(p, x_{n}\right)+\left(1-\delta_{n}\right) \phi\left(p, J_{r_{n}} w_{n}\right) \\
& \leq \delta_{n} \phi\left(p, x_{n}\right)+\left(1-\delta_{n}\right)\left(\phi\left(p, w_{n}\right)-\phi\left(J_{r_{n}} w_{n}, w_{n}\right)\right) \\
& \leq \delta_{n} \phi\left(p, x_{n}\right)+\left(1-\delta_{n}\right) \phi\left(p, w_{n}\right) \\
& \leq \delta_{n} \phi\left(p, x_{n}\right)+\left(1-\delta_{n}\right) \phi\left(p, x_{n}\right) \\
& =\phi\left(p, x_{n}\right),
\end{aligned}
$$


hence, we obtain

$$
\begin{aligned}
\phi\left(p, y_{n}\right)= & \phi\left(p, J^{-1}\left(\alpha_{n} J x_{n}+\beta_{n} J T_{n} x_{n}+\gamma_{n} J S_{n} z_{n}\right)\right) \\
= & \|p\|^{2}-2 \alpha_{n}\left\langle p, J x_{n}\right\rangle-2 \beta_{n}\left\langle p, J T_{n} x_{n}\right\rangle-2 \gamma_{n}\left\langle p, J S_{n} z_{n}\right\rangle \\
& +\left\|\alpha_{n} J x_{n}+\beta_{n} J T_{n} x_{n}+\gamma_{n} J S_{n} z_{n}\right\|^{2} \\
\leq & \|p\|^{2}-2 \alpha_{n}\left\langle p, J x_{n}\right\rangle-2 \beta_{n}\left\langle p, J T_{n} x_{n}\right\rangle-2 \gamma_{n}\left\langle p, J S_{n} z_{n}\right\rangle \\
& +\alpha_{n}\left\|J x_{n}\right\|^{2}+\beta_{n}\left\|J T_{n} x_{n}\right\|^{2}+\gamma_{n}\left\|J S_{n} z_{n}\right\|^{2} \\
= & \alpha_{n} \phi\left(p, x_{n}\right)+\beta_{n} \phi\left(p, T_{n} x_{n}\right)+\gamma_{n} \phi\left(p, S_{n} z_{n}\right) \\
\leq & \alpha_{n} \phi\left(p, x_{n}\right)+\beta_{n} \phi\left(p, x_{n}\right)+\gamma_{n} \phi\left(p, z_{n}\right) \\
\leq & \alpha_{n} \phi\left(p, x_{n}\right)+\beta_{n} \phi\left(p, x_{n}\right)+\gamma_{n} \phi\left(p, x_{n}\right) \\
= & \phi\left(p, x_{n}\right) .
\end{aligned}
$$

By (3.1), again,

$$
\phi\left(p, u_{n}\right)=\phi\left(p, K_{r_{n}} y_{n}\right) \leq \phi\left(p, y_{n}\right) \leq \phi\left(p, x_{n}\right)
$$

This shows that $p \in C_{n+1}$. Consequently, $\Theta \subset C_{n}$, for all $n \in \mathbb{N}$.

Next, we show that $\lim _{n \rightarrow \infty} \phi\left(x_{n}, x_{0}\right)$ exists. Since $x_{n}=\Pi_{C_{n}} x$, it follows from Lemma 2.7 that

$$
\phi\left(x_{n}, x\right) \leq \phi(p, x)-\phi\left(p, x_{n}\right) \leq \phi(p, x)
$$

for each $p \in \Theta \subset C_{n}$. Then, $\phi\left(x_{n}, x\right)$ is bounded. It implies that $\left\{x_{n}\right\}$ is bounded and $\left\{y_{n}\right\}$, $\left\{z_{n}\right\},\left\{w_{n}\right\}$, and $\left\{J_{r_{n}} w_{n}\right\}$ are also bounded.

From $x_{n}=\prod_{C_{n}} x$ and $x_{n+1} \in C_{n+1} \subset C_{n}$, we have

$$
\phi\left(x_{n}, x\right) \leq \phi\left(x_{n+1}, x\right), \quad \forall n \in \mathbb{N} .
$$

Therefore, $\left\{\phi\left(x_{n}, x\right)\right\}$ is nondecreasing. It follows that the limit of $\left\{\phi\left(x_{n}, x\right)\right\}$ exists, and from Lemma 2.7, we have

$$
\phi\left(x_{n+1}, x_{n}\right)=\phi\left(x_{n+1}, \Pi_{C_{n}} x\right) \leq \phi\left(x_{n+1}, x\right)-\phi\left(\Pi_{C_{n}} x, x\right)=\phi\left(x_{n+1}, x\right)-\phi\left(x_{n}, x\right),
$$

for all $n \in \mathbb{N}$. Thus, we have

$$
\lim _{n \rightarrow \infty} \phi\left(x_{n+1}, x_{n}\right)=0
$$


Since $x_{n+1}=\Pi_{C_{n+1}} x \in C_{n+1}$, it follows from the definition of $C_{n+1}$ that

$$
\phi\left(x_{n+1}, u_{n}\right) \leq \phi\left(x_{n+1}, x_{n}\right) \longrightarrow 0 .
$$

By Lemma 2.5, (3.13), and (3.14), we note that

$$
\lim _{n \rightarrow \infty}\left\|x_{n+1}-u_{n}\right\|=\lim _{n \rightarrow \infty}\left\|x_{n+1}-x_{n}\right\|=\lim _{n \rightarrow \infty}\left\|x_{n}-u_{n}\right\|=0 .
$$

Since $J$ is uniformly norm-to-norm continuous on the bounded set, we obtain

$$
\lim _{n \rightarrow \infty}\left\|J x_{n+1}-J u_{n}\right\|=\lim _{n \rightarrow \infty}\left\|J x_{n+1}-J x_{n}\right\|=\lim _{n \rightarrow \infty}\left\|J x_{n}-J u_{n}\right\|=0
$$

Since $x_{m}=\Pi_{C_{m}} \subset C_{n}$ for any positive integer $m \geq n$, it follows from Lemma 2.7 that

$$
\begin{aligned}
\phi\left(x_{m}, x_{n}\right)=\phi\left(x_{m}, \Pi_{C_{n}} x_{n}\right) & \leq \phi\left(x_{m}, x\right)-\phi\left(\Pi_{C_{n}} x_{n}, x\right) \\
& =\phi\left(x_{m}, x\right)-\phi\left(x_{n}, x\right) .
\end{aligned}
$$

Taking $m, n \rightarrow \infty$, we have $\phi\left(x_{m}, x_{n}\right) \rightarrow 0$ as $n \rightarrow \infty$. It follows from Lemma 2.5, that $\left\|x_{m}-x_{n}\right\| \rightarrow 0$ as $m, n \rightarrow \infty$. Hence, $\left\{x_{n}\right\}$ is a Cauchy sequence. Since $E$ is a Banach space and $C$ is closed and convex, we can assume that $x_{n} \rightarrow u \in C$ as $n \rightarrow \infty$.

Next, we show that $u \in\left(\cap_{n=1}^{\infty} F\left(T_{n}\right)\right) \cap\left(\cap_{n=1}^{\infty} F\left(S_{n}\right)\right)$.

Since $E$ is a uniformly smooth Banach space, we know that $E^{*}$ is a uniformly convex Banach space. Let $r=\sup _{n \in \mathbb{N}}\left\{\left\|x_{n}\right\|,\left\|T_{n} x_{n}\right\|,\left\|S_{n} z_{n}\right\|\right\}$. From Lemma 2.4, we have

$$
\begin{aligned}
\phi\left(p, u_{n}\right) \leq & \phi\left(p, y_{n}\right) \\
= & \phi\left(p, J^{-1}\left(\alpha_{n} J x_{n}+\beta_{n} J T_{n} x_{n}+\gamma_{n} J S_{n} z_{n}\right)\right) \\
= & \|p\|^{2}-2 \alpha_{n}\left\langle p, J x_{n}\right\rangle-2 \beta_{n}\left\langle p, J T_{n} x_{n}\right\rangle-2 \gamma_{n}\left\langle p, J S_{n} z_{n}\right\rangle \\
& +\left\|\alpha_{n} J x_{n}+\beta_{n} J T_{n} x_{n}+\gamma_{n} J S_{n} z_{n}\right\|^{2} \\
\leq & \|p\|^{2}-2 \alpha_{n}\left\langle p, J x_{n}\right\rangle-2 \beta_{n}\left\langle p, J T_{n} x_{n}\right\rangle-2 \gamma_{n}\left\langle p, J S_{n} z_{n}\right\rangle \\
& +\alpha_{n}\left\|J x_{n}\right\|^{2}+\beta_{n}\left\|J T_{n} x_{n}\right\|^{2}+\gamma_{n}\left\|J S_{n} z_{n}\right\|^{2}-\alpha_{n} \beta_{n} g\left(\left\|J T_{n} x_{n}-J x_{n}\right\|\right) \\
= & \alpha_{n} \phi\left(p, x_{n}\right)+\beta_{n} \phi\left(p, T_{n} x_{n}\right)+\gamma_{n} \phi\left(p, S_{n} z_{n}\right)-\alpha_{n} \beta_{n} g\left(\left\|J T_{n} x_{n}-J x_{n}\right\|\right) \\
\leq & \alpha_{n} \phi\left(p, x_{n}\right)+\beta_{n} \phi\left(p, x_{n}\right)+\gamma_{n} \phi\left(p, z_{n}\right)-\alpha_{n} \beta_{n} g\left(\left\|J T_{n} x_{n}-J x_{n}\right\|\right) \\
\leq & \alpha_{n} \phi\left(p, x_{n}\right)+\beta_{n} \phi\left(p, x_{n}\right)+\gamma_{n} \phi\left(p, x_{n}\right)-\alpha_{n} \beta_{n} g\left(\left\|J T_{n} x_{n}-J x_{n}\right\|\right) \\
= & \phi\left(p, x_{n}\right)-\alpha_{n} \beta_{n} g\left(\left\|J T_{n} x_{n}-J x_{n}\right\|\right) .
\end{aligned}
$$

This implies that

$$
\alpha_{n} \beta_{n} g\left(\left\|J T_{n} x_{n}-J x_{n}\right\|\right) \leq \phi\left(p, x_{n}\right)-\phi\left(p, u_{n}\right)
$$


On the other hand, we have

$$
\begin{aligned}
\phi\left(p, x_{n}\right)-\phi\left(p, u_{n}\right) & =\left\|x_{n}\right\|^{2}-\left\|u_{n}\right\|^{2}-2\left\langle p, J x_{n}-J u_{n}\right\rangle \\
& =\left\|x_{n}-u_{n}\right\|\left(\left\|x_{n}\right\|+\left\|u_{n}\right\|\right)+2\|p\|\left\|J x_{n}-J u_{n}\right\| .
\end{aligned}
$$

Noticing (3.15) and (3.16), we obtain

$$
\phi\left(p, x_{n}\right)-\phi\left(p, u_{n}\right) \longrightarrow 0, \quad \text { as } n \longrightarrow \infty
$$

Since $\lim \inf _{n \rightarrow \infty} \alpha_{n} \beta_{n}>0$ and (3.21), it follows from (3.19) that

$$
g\left(\left\|J T_{n} x_{n}-J x_{n}\right\|\right) \longrightarrow 0, \quad \text { as } n \longrightarrow \infty .
$$

It follows from the property of $g$ that

$$
\left\|J T_{n} x_{n}-J x_{n}\right\| \longrightarrow 0, \quad \text { as } n \longrightarrow \infty \text {. }
$$

Since $J^{-1}$ is uniformly norm-to-norm continuous on bounded sets, we see that

$$
\lim _{n \rightarrow \infty}\left\|T_{n} x_{n}-x_{n}\right\|=0 .
$$

Similarly, using the condition lim $\sup _{n \rightarrow \infty} \alpha_{n} \gamma_{n}>0$, one can obtain

$$
\lim _{n \rightarrow \infty}\left\|S_{n} z_{n}-x_{n}\right\|=0 .
$$

By (3.6), (3.8), and (3.18), we have

$$
\begin{aligned}
\phi\left(p, u_{n}\right) \leq & \alpha_{n} \phi\left(p, x_{n}\right)+\beta_{n} \phi\left(p, x_{n}\right)+\gamma_{n} \phi\left(p, z_{n}\right)-\alpha_{n} \beta_{n} g\left(\left\|J T_{n} x_{n}-J x_{n}\right\|\right) \\
\leq & \alpha_{n} \phi\left(p, x_{n}\right)+\beta_{n} \phi\left(p, x_{n}\right) \\
& +\gamma_{n}\left[\delta_{n} \phi\left(p, x_{n}\right)+\left(1-\delta_{n}\right) \phi\left(p, w_{n}\right)\right]-\alpha_{n} \beta_{n} g\left(\left\|J T_{n} x_{n}-J x_{n}\right\|\right) \\
\leq & \alpha_{n} \phi\left(p, x_{n}\right)+\beta_{n} \phi\left(p, x_{n}\right)+\gamma_{n} \delta_{n} \phi\left(p, x_{n}\right) \\
& +\gamma_{n}\left(1-\delta_{n}\right) \phi\left(p, w_{n}\right)-\alpha_{n} \beta_{n} g\left(\left\|J T_{n} x_{n}-J x_{n}\right\|\right) \\
\leq & \alpha_{n} \phi\left(p, x_{n}\right)+\beta_{n} \phi\left(p, x_{n}\right) \\
& +\gamma_{n} \delta_{n} \phi\left(p, x_{n}\right)+\gamma_{n}\left(1-\delta_{n}\right)\left[\phi\left(p, x_{n}\right)+2 \lambda_{n}\left(\frac{2}{c^{2}} \lambda_{n}-\alpha\right)\left\|B x_{n}-B p\right\|^{2}\right] \\
& -\alpha_{n} \beta_{n} g\left(\left\|J T_{n} x_{n}-J x_{n}\right\|\right)
\end{aligned}
$$


Journal of Applied Mathematics

$$
\begin{aligned}
\leq & \alpha_{n} \phi\left(p, x_{n}\right)+\beta_{n} \phi\left(p, x_{n}\right)+\gamma_{n} \delta_{n} \phi\left(p, x_{n}\right)+\gamma_{n}\left(1-\delta_{n}\right) \phi\left(p, x_{n}\right) \\
& +\gamma_{n}\left(1-\delta_{n}\right) 2 \lambda_{n}\left(\frac{2}{c^{2}} \lambda_{n}-\alpha\right)\left\|B x_{n}-B p\right\|^{2}-\alpha_{n} \beta_{n} g\left(\left\|J T_{n} x_{n}-J x_{n}\right\|\right) \\
\leq & \phi\left(p, x_{n}\right)+\gamma_{n}\left(1-\delta_{n}\right) 2 \lambda_{n}\left(\frac{2}{c^{2}} \lambda_{n}-\alpha\right)\left\|B x_{n}-B p\right\|^{2} .
\end{aligned}
$$

This implies that

$$
2 \lambda_{n}\left(\alpha-\frac{2}{c^{2}} \lambda_{n}\right)\left\|B x_{n}-B p\right\|^{2} \leq \frac{1}{\gamma_{n}\left(1-\delta_{n}\right)}\left[\phi\left(p, x_{n}\right)-\phi\left(p, u_{n}\right)\right] .
$$

By assumption, $\lim \inf _{n \rightarrow \infty} \gamma_{n}\left(1-\delta_{n}\right)>0$ and (3.21), we get that

$$
\lim _{n \rightarrow \infty}\left\|B x_{n}-B p\right\|=0 .
$$

From Lemma 2.7, Lemma 2.8, and (3.5), we have

$$
\begin{aligned}
\phi\left(x_{n}, w_{n}\right) & =\phi\left(x_{n}, \Pi_{C} v_{n}\right) \\
& \leq \phi\left(x_{n}, v_{n}\right) \\
& =\phi\left(x_{n}, J^{-1}\left(J x_{n}-\lambda_{n} B x_{n}\right)\right) \\
& =V\left(x_{n}, J x_{n}-\lambda_{n} B x_{n}\right) \\
& \leq V\left(x_{n},\left(J x_{n}-\lambda_{n} B x_{n}\right)+\lambda_{n} B x_{n}\right)-2\left\langle J^{-1}\left(J x_{n}-\lambda_{n} B x_{n}\right)-x_{n}, \lambda_{n} B x_{n}\right\rangle \\
& =V\left(x_{n}, J x_{n}\right)-2 \lambda_{n}\left\langle v_{n}-x_{n}, B x_{n}\right\rangle \\
& =\phi\left(x_{n}, x_{n}\right)+2\left\langle v_{n}-x_{n}, \lambda_{n} B x_{n}\right\rangle \\
& \leq \frac{4}{c^{2}} \lambda_{n}^{2}\left\|B x_{n}-B p\right\|^{2} .
\end{aligned}
$$

By Lemma 2.8 and Lemma 2.13, we have

$$
\begin{aligned}
\phi\left(x_{n}, z_{n}\right) & =\phi\left(x_{n}, J^{-1}\left(\delta_{n} J x_{n}+\left(1-\delta_{n}\right) J\left(J_{r_{n}} w_{n}\right)\right)\right) \\
& =V\left(x_{n}, \delta_{n} J x_{n}+\left(1-\delta_{n}\right) J\left(J_{r_{n}} w_{n}\right)\right) \\
& \leq \delta_{n} V\left(x_{n}, J x_{n}\right)+\left(1-\delta_{n}\right) V\left(x_{n}, J\left(J_{r_{n}} w_{n}\right)\right) \\
& =\delta_{n} \phi\left(x_{n}, x_{n}\right)+\left(1-\delta_{n}\right) \phi\left(x_{n}, J_{r_{n}} w_{n}\right) \\
& =\delta_{n} \phi\left(x_{n}, x_{n}\right)+\left(1-\delta_{n}\right)\left(\phi\left(x_{n}, w_{n}\right)-\phi\left(J_{r_{n}} w_{n}, w_{n}\right)\right) \\
& =\left(1-\delta_{n}\right) \phi\left(x_{n}, w_{n}\right) \\
& \leq\left(1-\delta_{n}\right) \frac{4}{c^{2}} \lambda_{n}^{2}\left\|B x_{n}-B p\right\|^{2} .
\end{aligned}
$$


From Lemma 2.5 and (3.28), we obtain

$$
\lim _{n \rightarrow \infty}\left\|x_{n}-w_{n}\right\|=\lim _{n \rightarrow \infty}\left\|x_{n}-z_{n}\right\|=0 .
$$

Since $J$ is uniformly norm-to-norm continuous on bounded sets, we note that

$$
\lim _{n \rightarrow \infty}\left\|J x_{n}-J w_{n}\right\|=\lim _{n \rightarrow \infty}\left\|J x_{n}-J z_{n}\right\|=0
$$

Since $x_{n} \rightarrow u$ as $n \rightarrow \infty, z_{n} \rightarrow u$ as $n \rightarrow \infty$. Combining (3.15), (3.25), and (3.28), we also obtain

$$
\left\|S_{n} z_{n}-z_{n}\right\| \leq\left\|S_{n} z_{n}-x_{n}\right\|+\left\|x_{n}-z_{n}\right\| \longrightarrow 0 \text { as } n \longrightarrow \infty
$$

By (3.15) and (3.31), we obtain that

$$
\left\|z_{n+1}-z_{n}\right\| \leq\left\|z_{n+1}-x_{n+1}\right\|+\left\|x_{n+1}-x_{n}\right\|+\left\|x_{n}-z_{n}\right\| \longrightarrow 0 \quad \text { as } n \longrightarrow \infty .
$$

By (3.15), (3.24), (3.33), and (3.34), and $\left\{T_{n}\right\},\left\{S_{n}\right\}$ satisfies the NST*-condition and $x_{n} \rightarrow p$, then we have $p \in\left(\cap_{n=1}^{\infty} F\left(T_{n}\right)\right) \cap\left(\cap_{n=1}^{\infty} F\left(S_{n}\right)\right)$.

Since $\left\{x_{n}\right\}$ is bounded, there exists a subsequence $\left\{x_{n_{i}}\right\}$ of $\left\{x_{n}\right\}$ such that $x_{n_{i}} \rightarrow u \in C$. It follows from (3.31) that we have $w_{n_{i}} \rightarrow u$ as $i \rightarrow \infty$. Next, we show that $u \in A^{-1} 0$.

By (3.6), (3.8), and (3.9), we obtain

$$
\begin{aligned}
\phi\left(p, u_{n}\right) & \leq \phi\left(p, y_{n}\right) \\
& \leq \alpha_{n} \phi\left(p, x_{n}\right)+\beta_{n} \phi\left(p, x_{n}\right)+\gamma_{n} \phi\left(p, z_{n}\right) \\
& \leq \alpha_{n} \phi\left(p, x_{n}\right)+\beta_{n} \phi\left(p, x_{n}\right)+\gamma_{n}\left[\delta_{n} \phi\left(p, x_{n}\right)+\left(1-\delta_{n}\right)\left(\phi\left(p, w_{n}\right)-\phi\left(J_{r_{n}} w_{n}, w_{n}\right)\right)\right] \\
& \leq \alpha_{n} \phi\left(p, x_{n}\right)+\beta_{n} \phi\left(p, x_{n}\right)+\gamma_{n}\left[\delta_{n} \phi\left(p, x_{n}\right)+\left(1-\delta_{n}\right)\left(\phi\left(p, x_{n}\right)-\phi\left(J_{r_{n}} w_{n}, w_{n}\right)\right)\right] \\
& \leq \phi\left(p, x_{n}\right)-\gamma_{n}\left(1-\delta_{n}\right) \phi\left(J_{r_{n}} w_{n}, w_{n}\right) .
\end{aligned}
$$

This implies that

$$
\gamma_{n}\left(1-\delta_{n}\right) \phi\left(J_{r_{n}} w_{n}, w_{n}\right) \leq \phi\left(p, x_{n}\right)-\phi\left(p, u_{n}\right)
$$

By (3.21), we have

$$
\lim _{n \rightarrow \infty}\left\|J_{r_{n}} w_{n}-w_{n}\right\|=0
$$

Since $J$ is uniformly norm-to-norm continuous on bounded sets, we note that

$$
\lim _{n \rightarrow \infty}\left\|J J_{r_{n}} w_{n}-J w_{n}\right\|=0
$$


Indeed, since $\lim \inf _{n \rightarrow \infty} r_{n}>0$, it follows from (3.38) that

$$
\lim _{n \rightarrow \infty}\left\|A_{r_{n}} w_{n}\right\|=\lim _{n \rightarrow \infty} \frac{1}{r_{n}}\left\|J w_{n}-J\left(J_{r_{n}} w_{n}\right)\right\|=0 .
$$

If $\left(w, w^{*}\right) \in A$, then it holds from the monotonicity of $A$ that

$$
\left\langle w-w_{n_{i}}, w^{*}-A_{r_{n_{i}}} w_{n_{i}}\right\rangle \geq 0
$$

for all $i \in \mathbb{N}$. Letting $i \rightarrow \infty$, we get $\left\langle w-u, w^{*}\right\rangle \geq 0$. Then, the maximality of $A$ implies $u \in A^{-1} 0$.

Next, we show that $u \in \operatorname{VI}(C, B)$. Let $K \subset E \times E^{*}$ be an operator as follows:

$$
K v=\left\{\begin{array}{lc}
B v+N_{C}(v), & v \in C \\
\emptyset, & \text { otherwise }
\end{array}\right.
$$

By Theorem 2.14, $K$ is maximal monotone and $K^{-1} 0=\mathrm{VI}(C, B)$.

Let $(v, w) \in G(K)$. Since $w \in K v=B v+N_{C}(v)$, we get $w-B v \in N_{C}(v)$. From $w_{n} \in C$, we have

$$
\left\langle v-w_{n}, w-K v\right\rangle \geq 0
$$

On the other hand, since $w_{n}=\Pi_{C} J^{-1}\left(J x_{n}-\lambda_{n} B x_{n}\right)$, then by Lemma 2.6, we have

$$
\left\langle v-w_{n}, J w_{n}-\left(J x_{n}-\lambda_{n} B x_{n}\right)\right\rangle \geq 0,
$$

thus

$$
\left\langle v-w_{n}, \frac{J x_{n}-J w_{n}}{\lambda_{n}}-B x_{n}\right\rangle \leq 0
$$

It follows from (3.42) and (3.44) that

$$
\begin{aligned}
\left\langle v-w_{n}, w\right\rangle & \geq\left\langle v-w_{n}, B v\right\rangle \\
& \geq\left\langle v-w_{n}, B v\right\rangle+\left\langle v-w_{n}, \frac{J x_{n}-J w_{n}}{\lambda_{n}}-B x_{n}\right\rangle \\
& =\left\langle v-w_{n}, B v-B x_{n}\right\rangle+\left\langle v-w_{n}, \frac{J x_{n}-J w_{n}}{\lambda_{n}}\right\rangle \\
& =\left\langle v-w_{n}, B v-B w_{n}\right\rangle+\left\langle v-w_{n}, B w_{n}-B x_{n}\right\rangle+\left\langle v-w_{n}, \frac{J x_{n}-J w_{n}}{\lambda_{n}}\right\rangle \\
& \geq-\left\|v-w_{n}\right\| \frac{\left\|w_{n}-x_{n}\right\|}{\alpha}-\left\|v-w_{n}\right\| \frac{\left\|J x_{n}-J w_{n}\right\|}{a} \\
& \geq-M\left(\frac{\left\|w_{n}-x_{n}\right\|}{\alpha}+\frac{\left\|J x_{n}-J w_{n}\right\|}{a}\right)
\end{aligned}
$$


where $M=\sup _{n>1}\left\{\left\|v-w_{n}\right\|\right\}$. From (3.31) and (3.32), we obtain $\langle v-u, w\rangle \geq 0$. By the maximality of $K$, we have $u \in K^{-1} 0$ and hence $u \in \operatorname{VI}(C, B)$.

Next, we show that $u \in \Omega$. From $u_{n}=K_{r_{n}} y_{n}$ and Lemma 2.12, we obtain

$$
\begin{aligned}
\phi\left(u_{n}, y_{n}\right) & =\phi\left(K_{r_{n}} y_{n}, y_{n}\right) \\
& \leq \phi\left(u, y_{n}\right)-\phi\left(u, K_{r_{n}} y_{n}\right) \\
& \leq \phi\left(u, x_{n}\right)-\phi\left(u, K_{r_{n}} y_{n}\right) \\
& \leq \phi\left(u, x_{n}\right)-\phi\left(u, u_{n}\right) .
\end{aligned}
$$

On the other hand, we have

$$
\begin{aligned}
\phi\left(u, x_{n}\right)-\phi\left(u, u_{n}\right) & =\left\|x_{n}\right\|^{2}-\left\|u_{n}\right\|^{2}-2\left\langle u, J x_{n}-J u_{n}\right\rangle \\
& =\left\|x_{n}-u_{n}\right\|\left(\left\|x_{n}\right\|+\left\|u_{n}\right\|\right)+2\|u\|\left\|J x_{n}-J u_{n}\right\| .
\end{aligned}
$$

Noticing (3.15) and (3.16), we obtain

$$
\phi\left(u, x_{n}\right)-\phi\left(u, u_{n}\right) \longrightarrow 0, \quad \text { as } n \longrightarrow \infty \text {. }
$$

It follows that

$$
\phi\left(u_{n}, y_{n}\right) \longrightarrow 0, \quad \text { as } n \longrightarrow \infty
$$

By Lemma 2.5, we have

$$
\lim _{n \rightarrow \infty}\left\|u_{n}-y_{n}\right\|=0
$$

Since $J$ is uniformly norm-to-norm continuous on bounded sets, we get

$$
\lim _{n \rightarrow \infty}\left\|J u_{n}-J y_{n}\right\|=0
$$

From the assumption lim $\inf _{n \rightarrow \infty} r_{n}>a$, we get

$$
\lim _{n \rightarrow \infty} \frac{\left\|J u_{n}-J y_{n}\right\|}{r_{n}}=0 .
$$

Noticing that $u_{n}=K_{r_{n}} y_{n}$, we have

$$
H\left(u_{n}, y\right)+\frac{1}{r_{n}}\left\langle y-u_{n}, J u_{n}-J y_{n}\right\rangle \geq 0, \quad \forall y \in C .
$$


Hence,

$$
H\left(u_{n_{i}}, y\right)+\frac{1}{r_{n_{i}}}\left\langle y-u_{n_{i}}, J u_{n_{i}}-J y_{n_{i}}\right\rangle \geq 0, \quad \forall y \in C
$$

From the (A2), we note that

$$
\left\|y-u_{n_{i}}\right\| \frac{\left\|J u_{n_{i}}-J y_{n_{i}}\right\|}{r_{n_{i}}} \geq \frac{1}{r_{n_{i}}}\left\langle y-u_{n_{i}}, J u_{n_{i}}-J y_{n_{i}}\right\rangle \geq-H\left(u_{n_{i}}, y\right) \geq H\left(y, u_{n_{i}}\right), \quad \forall y \in C .
$$

Taking the limit as $n \rightarrow \infty$ in the above inequality, and from (A4) and $u_{n_{i}} \rightarrow u$, we have $H(y, u) \leq 0$, for all $y \in C$. For $0<t<1$ and $y \in C$, define $y_{t}=t y+(1-t) u$. Noticing that $y, u \in C$, we obtain $y_{t} \in C$, which yields that $H\left(y_{t}, u\right) \leq 0$. It follows from (A1) that

$$
0=H\left(y_{t}, y_{t}\right) \leq t H\left(y_{t}, y\right)+(1-t) H\left(y_{t}, u\right) \leq t H\left(y_{t}, y\right)
$$

That is, $H\left(y_{t}, y\right) \geq 0$.

Let $t \downarrow 0$, from (A3), we obtain $H(u, y) \geq 0$, for all $y \in C$. This implies that $u \in \Omega$. Hence, $u \in \Theta:=\left(\cap_{n=1}^{\infty} F\left(T_{n}\right)\right) \cap\left(\cap_{n=1}^{\infty} F\left(S_{n}\right)\right) \cap \Omega \cap V I(C, B) \cap A^{-1}(0)$.

Finally, we show that $u=\Pi_{\Theta} x$. Indeed, from $x_{n}=\Pi_{C_{n}} x$ and Lemma 2.6, we have

$$
\left\langle J x-J x_{n}, x_{n}-z\right\rangle \geq 0, \quad \forall z \in C_{n} .
$$

Since $\Theta \subset C_{n}$, we also have

$$
\left\langle J x-J x_{n}, x_{n}-p\right\rangle \geq 0, \quad \forall p \in \Theta .
$$

Taking limit $n \rightarrow \infty$, we obtain

$$
\langle J x-J u, u-p\rangle \geq 0, \quad \forall p \in \Theta .
$$

By again Lemma 2.6, we can conclude that $u=\Pi_{\Theta} x_{0}$. This completes the proof.

Corollary 3.2. Let $E$ be a 2-uniformly convex and uniformly smooth Banach space, and let $C$ be a nonempty closed convex subset of $E$. Let $F$ be a bifunction from $C \times C$ to $\mathbb{R}$ satisfying (A1)-(A4), let $\varphi: C \rightarrow \mathbb{R}$ be a proper lower semicontinuous and convex function, and let $A: E \rightarrow E^{*}$ be a maximal monotone operator satisfying $D(A) \subset$ E. Let $J_{r}=(J+r A)^{-1} J$ for $r>0$, let $B$ be an $\alpha$-inverse-strongly monotone operator of $E$ into $E^{*}$, and let $Y: C \rightarrow E^{*}$ be a continuous and monotone mapping. Let $T$ and $S$ be two quasi- $\phi$-nonexpansive mappings of $E$ into itself with 
$F:=F(T) \cap F(S) \cap \Omega \cap \operatorname{VI}(C, B) \cap A^{-1}(0) \neq \emptyset$ and $\|B y\| \leq\|B y-B u\|$ for all $y \in C$ and $u \in \Theta$. Let $\left\{x_{n}\right\}$ be a sequence generated by $x_{1}=x \in E$, and

$$
\begin{aligned}
w_{n} & =\Pi_{C} J^{-1}\left(J x_{n}-\lambda_{n} B x_{n}\right), \\
z_{n} & =J^{-1}\left(\delta_{n} J\left(x_{n}\right)+\left(1-\delta_{n}\right) J\left(J_{r_{n}} w_{n}\right)\right), \\
y_{n} & =J^{-1}\left(\alpha_{n} J x_{n}+\beta_{n} J T x_{n}+\gamma_{n} J S z_{n}\right), \\
u_{n} & \in C \text { such that } F\left(u_{n}, y\right)+\left\langle Y u_{n}, y-u_{n}\right\rangle+\varphi(y)-\varphi\left(u_{n}\right) \\
C_{n+1} & =\left\{z \in C: \phi\left(z, u_{n}\right) \leq \phi\left(z, x_{n}\right)\right\}, \\
x_{n+1} & =\Pi_{C_{n+1}} x,
\end{aligned}
$$

for all $n \in \mathbb{N}$. If the coefficient sequence $\left\{\alpha_{n}\right\},\left\{\beta_{n}\right\}$, and $\left\{\gamma_{n}\right\}$ and $\left\{\delta_{n}\right\} \subset[0,1],\left\{r_{n}\right\} \subset(0, \infty)$ satisfy $\alpha_{n}+\beta_{n}+\gamma_{n}=1, \lim _{\inf _{n \rightarrow \infty}} \alpha_{n} \beta_{n}>0, \lim _{\inf _{n \rightarrow \infty}} \alpha_{n} \gamma_{n}>0, \lim _{n \rightarrow \infty} \inf _{n \rightarrow \infty} \gamma_{n}\left(1-\delta_{n}\right)>0$, $\lim _{\inf _{n \rightarrow \infty}} r_{n}>0$ and $\left\{\lambda_{n}\right\} \subset[a, b]$ for some $a, b$ with $0<a<b<\left(c^{2} \alpha\right) / 2,1 / c$ is the 2-uniformly convexity constant of $E$. Then, the sequence $\left\{x_{n}\right\}$ converges strongly to $\Pi_{\Theta} x$.

Remark 3.3. Theorem 3.1 and Corollary 3.2 extended and improved the results of [40] by extending the mapping from two-relatively quasi-nonexpansive mappings to two countable families of quasi- $\phi$-nonexpansive mappings and improving the iterative scheme to be more general, and finally, we proposed the better new conditions for the coefficient sequences which was imposed in our algorithm.

\section{Applications}

\subsection{A Zero Point of Inverse-Strongly Monotone Operators}

Next, we consider the problem of finding a zero point of an inverse-strongly monotone operator of $E$ into $E^{*}$. Assume that $B$ satisfies the following conditions:

(C1) $B$ is $\alpha$-inverse-strongly monotone,

(C2) $B^{-1} 0=\{u \in E: B u=0\} \neq \emptyset$.

Hence, we also have the following result.

Corollary 4.1. Let E be a 2-uniformly convex and uniformly smooth Banach space, and let $C$ be a nonempty closed convex subset of $E$. Let $F$ be a bifunction from $C \times C$ to $\mathbb{R}$ satisfying (A1)-(A4), let $\varphi: C \rightarrow \mathbb{R}$ be a proper lower semicontinuous and convex function, and let $A: E \rightarrow E^{*}$ be a maximal monotone operator satisfying $D(A) \subset$ E. Let $J_{r}=(J+r A)^{-1} J$ for $r>0$, let $B$ be an $\alpha$-inverse-strongly monotone operator of $E$ into $E^{*}$, and let $Y: C \rightarrow E^{*}$ be a continuous and monotone mapping. Let $T$ and $S$ be two quasi- $\phi$-nonexpansive mappings of $E$ into itself with

$$
\Theta:=F(T) \cap F(S) \cap \Omega \cap B^{-1}(0) \cap A^{-1}(0) \neq \emptyset .
$$


Let $\left\{x_{n}\right\}$ be a sequence generated by $x_{1}=x \in E$, and

$$
\begin{aligned}
w_{n} & =\Pi_{C} J^{-1}\left(J x_{n}-\lambda_{n} B x_{n}\right), \\
z_{n} & =J^{-1}\left(\delta_{n} J\left(x_{n}\right)+\left(1-\delta_{n}\right) J\left(J_{r_{n}} w_{n}\right)\right), \\
y_{n} & =J^{-1}\left(\alpha_{n} J x_{n}+\beta_{n} J T x_{n}+\gamma_{n} J S z_{n}\right), \\
u_{n} & \in C \text { such that } F\left(u_{n}, y\right)+\left\langle Y u_{n}, y-u_{n}\right\rangle+\varphi(y)-\varphi\left(u_{n}\right) \\
& +\frac{1}{r_{n}}\left\langle y-u_{n}, J u_{n}-J y_{n}\right\rangle \geq 0, \quad \forall y \in C, \\
C_{n+1} & =\left\{z \in C: \phi\left(z, u_{n}\right) \leq \phi\left(z, x_{n}\right)\right\}, \\
x_{n+1} & =\prod_{C_{n+1}} x,
\end{aligned}
$$

for all $n \in \mathbb{N}$, where $\Pi_{C}$ is the generalized projection from $E$ onto $C, J$ is the duality mapping on $E$. If the coefficient sequence $\left\{\alpha_{n}\right\},\left\{\beta_{n}\right\},\left\{\gamma_{n}\right\}$, and $\left\{\delta_{n}\right\} \subset[0,1],\left\{r_{n}\right\} \subset(0, \infty)$ satisfy $\alpha_{n}+\beta_{n}+\gamma_{n}=1$, $\lim _{\inf } n_{n \rightarrow \infty} \alpha_{n} \beta_{n}>0, \lim _{\inf _{n \rightarrow \infty}} \alpha_{n} \gamma_{n}>0, \lim _{\inf } \rightarrow_{n \rightarrow \infty} \gamma_{n}\left(1-\delta_{n}\right)>0, \lim _{\inf _{n \rightarrow \infty}} r_{n}>0$, and $\left\{\lambda_{n}\right\} \subset[a, b]$ for some $a, b$ with $0<a<b<c^{2} \alpha / 2,1 / c$ is the 2-uniformly convexity constant of $E$, then the sequence $\left\{x_{n}\right\}$ converges strongly to $\Pi_{\Theta} x$.

Proof. Setting $\widetilde{B} x \equiv 0$, for all $x \in C$, then $D(\widetilde{B})=E$ and hence $C=E$ in Corollary 3.2, we also get $\Pi_{E}=I$. We also have $\operatorname{VI}(B, C)=\operatorname{VI}(B, E)=\{x \in E: B x=0\} \neq \emptyset$, and then, the condition $\|B y\| \leq\|B y-B u\|$ holds for all $y \in E$ and $u \in B^{-1} 0$. So, we obtain the result.

\subsection{Complementarity Problems}

Let $K$ be a nonempty, closed convex cone in $E$. We define the polar $K^{*}$ of $K$ as follows:

$$
K^{*}=\left\{y^{*} \in E^{*}:\left\langle x, y^{*}\right\rangle \geq 0, \forall x \in K\right\}
$$

If $A: K \rightarrow E^{*}$ is an operator, then an element $u \in K$ is called a solution of the complementarity problem $([43])$ if

$$
A u \in K^{*}, \quad\langle u, A u\rangle=0 .
$$

The set of solutions of the complementarity problem is denoted by $C(A, K)$.

Corollary 4.2. Let E be a 2-uniformly convex and uniformly smooth Banach space, and let $K$ be a nonempty closed convex subset of $E$. Let $F$ be a bifunction from $K \times K$ to $\mathbb{R}$ satisfying (A1)-(A4), let $\varphi: K \rightarrow \mathbb{R}$ be a proper lower semicontinuous and convex function, and let $A: E \rightarrow E^{*}$ be a maximal monotone operator satisfying $D(A) \subset$ E. Let $J_{r}=(J+r A)^{-1} J$ for $r>0$, let B be an $\alpha$-inverse-strongly monotone operator of $E$ into $E^{*}$, and let $Y: K \rightarrow E^{*}$ be a continuous and monotone mapping. Let $T$ and $S$ be two quasi- $\phi$-nonexpansive mappings of $E$ into itself with

$$
\Theta:=F(T) \cap F(S) \cap \Omega \cap C(B, K) \cap A^{-1}(0) \neq \emptyset,
$$


and $\|B y\| \leq\|B y-B u\|$ for all $y \in K$ and $u \in \Theta$. Let $\left\{x_{n}\right\}$ be a sequence generated by $x_{1}=x \in E$, and

$$
\begin{aligned}
w_{n} & =\Pi_{K} J^{-1}\left(J x_{n}-\lambda_{n} B x_{n}\right), \\
z_{n} & =J^{-1}\left(\delta_{n} J\left(x_{n}\right)+\left(1-\delta_{n}\right) J\left(J_{r_{n}} w_{n}\right)\right), \\
y_{n} & =J^{-1}\left(\alpha_{n} J x_{n}+\beta_{n} J T x_{n}+\gamma_{n} J S z_{n}\right), \\
u_{n} & \in K \text { such that } F\left(u_{n}, y\right)+\left\langle Y u_{n}, y-u_{n}\right\rangle+\varphi(y)-\varphi\left(u_{n}\right) \\
\qquad & +\frac{1}{r_{n}}\left\langle y-u_{n}, J u_{n}-J y_{n}\right\rangle \geq 0, \quad \forall y \in K, \\
K_{n+1} & =\left\{z \in K: \phi\left(z, u_{n}\right) \leq \phi\left(z, x_{n}\right)\right\} \\
x_{n+1} & =\Pi_{K_{n+1}} x,
\end{aligned}
$$

for all $n \in \mathbb{N}$, where $\Pi_{K}$ is the generalized projection from $E$ onto $K, J$ is the duality mapping on $E$. If the coefficient sequence $\left\{\alpha_{n}\right\},\left\{\beta_{n}\right\},\left\{\gamma_{n}\right\}$, and $\left\{\delta_{n}\right\} \subset[0,1],\left\{r_{n}\right\} \subset(0, \infty)$ satisfy $\alpha_{n}+\beta_{n}+\gamma_{n}=1$, $\liminf _{n \rightarrow \infty} \alpha_{n} \beta_{n}>0, \lim _{\inf _{n \rightarrow \infty}} \alpha_{n} \gamma_{n}>0, \liminf _{n \rightarrow \infty} \gamma_{n}\left(1-\delta_{n}\right)>0, \liminf _{n \rightarrow \infty} r_{n}>0$, and $\left\{\lambda_{n}\right\} \subset[a, b]$ for some $a, b$ with $0<a<b<c^{2} \alpha / 2,1 / c$ is the 2-uniformly convexity constant of $E$, then the sequence $\left\{x_{n}\right\}$ converges strongly to $\Pi_{\Theta} x$.

Proof. As in the proof of Takahashi in [43, Lemma 7.11], we have $\operatorname{VI}(B, K)=C(B, K)$. So, we obtain the above result.

\section{Acknowledgments}

The first author was supported by the Centre of Excellence in Mathematics, the Commission on Higher Education, Ministry of Education, Thailand. The second author was supported by the Higher Education Research Promotion and National Research University Project of Thailand, Office of the Higher Education Commission (NRU-CSEC no. 54000267). Finally, the authors also thank the referees for their valuable comments and suggestions.

\section{References}

[1] Y. Yao and N. Shahzad, "New methods with perturbations for non-expansive mappings in Hilbert spaces," Fixed Point Theory and Applications. In press.

[2] Y. Yao and N. Shahzad, "Strong convergence of a proximalpoint algorithm with general errors," Optimization Letters. In press.

[3] Y. Yao, Y. C. Liou, and C. P. Chen, "Algorithms construction for nonexpansive mappings and inversestrongly monotone mappings," Taiwanese Journal of Mathematics, vol. 15, no. 5, pp. 1979-1998, 2011.

[4] Y. J. Cho, N. Petrot, and S. Suantai, "Fixed point theorems for nonexpansive mappings with applications to generalized equilibrium and system of nonlinear variational inequalities problems," Journal of Nonlinear Analysis and Optimization, vol. 1, no. 1, pp. 45-53, 2010.

[5] U. Kamraksa and R. Wangkeeree, "A new hybrid method for solving generalized equilibrium problem and common fixed points of asymptotically quasi nonexpansive mappings in Banach spaces," Journal of Nonlinear Analysis and Optimization, vol. 1, no. 1, pp. 55-69, 2010.

[6] T. Jitpeera and P. Kumam, "An extragradient type method for a system of equilibrium problems, variational inequality problems and fixed points of finitely many nonexpansive mappings," Journal of Nonlinear Analysis and Optimization, vol. 1, no. 1, pp. 71-91, 2010. 
[7] S. Plubtieng and T. Thammathiwat, "Shrinking projection methods for a family of relatively nonexpansive mappings, equilibrium problems and variational inequality problems in Banach spaces," Journal of Nonlinear Analysis and Optimization, vol. 1, no. 1, pp. 97-100, 2010.

[8] P. Markshoe, R. Wangkeeree, and U. Kamraksa, "The shrinking projection method for Generalized mixed Equilibrium Problems and Fixed Point Problems in Banach Spaces," Journal of Nonlinear Analysis and Optimization, vol. 1, no. 1, pp. 111-129, 2010.

[9] B. Rodjanadid, "An iterative method for finding common solutions of generalized mixed equilibrium problems and fixed point problems," Journal of Nonlinear Analysis and Optimization, vol. 1, no. 1, pp. 151-167, 2010.

[10] W. Nilsrakoo and S. Saejung, "Strong convergence to common fixed points of countable relatively quasi-nonexpansive mappings," Fixed Point Theory and Applications, vol. 2008, Article ID 312454, 19 pages, 2008.

[11] Y. Su, D. Wang, and M. Shang, "Strong convergence of monotone hybrid algorithm for hemi-relatively nonexpansive mappings," Fixed Point Theory and Applications, vol. 2008, Article ID 617248, 12 pages, 2008.

[12] H. Zegeye and N. Shahzad, "Strong convergence theorems for monotone mappings and relatively weak nonexpansive mappings," Nonlinear Analysis. Theory, Methods E Applications, vol. 70, no. 7, pp. 2707-2716, 2009.

[13] D. Butnariu, S. Reich, and A. J. Zaslavski, “Asymptotic behavior of relatively nonexpansive operators in Banach spaces," Journal of Applied Analysis, vol. 7, no. 2, pp. 151-174, 2001.

[14] Y. Censor and S. Reich, "Iterations of paracontractions and firmly nonexpansive operators with applications to feasibility and optimization," Optimization, vol. 37, no. 4, pp. 323-339, 1996.

[15] W. A. Kirk, "A fixed point theorem for mappings which do not increase distances," The American Mathematical Monthly, vol. 72, pp. 1004-1006, 1965.

[16] S. Reich, "A weak convergence theorem for the alternating method with Bregman distances," in Theory and Applications of Nonlinear Operators of Accretive and Monotone Type, A. G. Kartsatos, Ed., vol. 178, pp. 313-318, Marcel Dekker, New York, NY, USA, 1996.

[17] E. Blum and W. Oettli, "From optimization and variational inequalities to equilibrium problems," The Mathematics Student, vol. 63, no. 1-4, pp. 123-145, 1994.

[18] S. D. Flam and A. S. Antipin, "Equilibrium programming using proximal-like algorithms," Mathematical Programming, vol. 78, no. 1, pp. 29-41, 1997.

[19] A. Moudafi and M. Thera, "Proximal and dynamical approaches to equilibrium problems," in Lecture note in Economics and Mathematical Systems, vol. 477, pp. 187-201, Springer-Verlag, New York, NY, USA, 1999.

[20] S. Takahashi and W. Takahashi, "Viscosity approximation methods for equilibrium problems and fixed point problems in Hilbert spaces," Journal of Mathematical Analysis and Applications, vol. 331, no. 1, pp. 506-515, 2007.

[21] Y. Yao, R. Chen, and Y. C. Liou, "A unified implicit algorithm for solving the triple-hierarchical constrained optimization problem," Mathematical and Computer Modelling, vol. 55, no. 3-4, pp. 1506-1515, 2012.

[22] P. L. Combettes and S. A. Hirstoaga, "Equilibrium programming in Hilbert spaces," Journal of Nonlinear and Convex Analysis, vol. 6, no. 1, pp. 117-136, 2005.

[23] S. Saewan and P. Kumam, "Modified hybrid block iterative algorithm for convex feasibility problems and generalized equilibrium problems for uniformly quasi- $\phi$-asymptotically nonexpansive mappings," Abstract and Applied Analysis, vol. 2010, Article ID 357120, 22 pages, 2010.

[24] S. Saewan, P. Kumam, and K. Wattanawitoon, "Convergence theorem based on a new hybrid projection method for finding a common solution of generalized equilibrium and variational inequality problems in Banach spaces," Abstract and Applied Analysis, vol. 2010, Article ID 734126, 25 pages, 2010.

[25] A. Tada and W. Takahashi, "Strong convergence theorem for an equilibrium problem and a nonexpansive mapping," in Nonlinear Analysis and Convex Analysis, W. Takahashi and T. Tanaka, Eds., pp. 609617, Yokohama Publ., Yokohama, 2007.

[26] A. Tada and W. Takahashi, "Weak and strong convergence theorems for a nonexpansive mapping and an equilibrium problem," Journal of Optimization Theory and Applications, vol. 133, no. 3, pp. 359-370, 2007.

[27] G. Stampacchia, "Formes bilineaires coercitives sur les ensembles convexes," Comptes Rendus de l'Académie des Sciences, vol. 258, pp. 4413-4416, 1964. 
[28] Y. Yao, Y. C. Liou, S. M. Kang, and Y. Yu, “Algorithms with strong convergence for a system of nonlinear variational inequalities in Banach spaces," Nonlinear Analysis, Theory, Methods and Applications, vol. 74, no. 17, pp. 6024-6034, 2011.

[29] Y. Yao, Y. J. Cho, and Y. C. Liou, “Algorithms of common solutions for variational inclusions, mixed equilibrium problems and fixed point problems," European Journal of Operational Research, vol. 212, no. 2, pp. 242-250, 2011.

[30] B. Halpern, "Fixed points of nonexpanding maps," Bulletin of the American Mathematical Society, vol. 73, pp. 957-961, 1967.

[31] K. Aoyama, Y. Kimura, W. Takahashi, and M. Toyoda, "Approximation of common fixed points of a countable family of nonexpansive mappings in a Banach space," Nonlinear Analysis. Theory, Methods $\mathcal{E}$ Applications, vol. 67, no. 8, pp. 2350-2360, 2007.

[32] K. Nakajo, K. Shimoji, and W. Takahashi, “On strong convergence by the hybrid method for families of mappings in Hilbert spaces," Nonlinear Analysis. Theory, Methods \& Applications, vol. 71, no. 1-2, pp. 112-119, 2009.

[33] H. Iiduka, W. Takahashi, and M. Toyoda, "Approximation of solutions of variational inequalities for monotone mappings," Panamerican Mathematical Journal, vol. 14, no. 2, pp. 49-61, 2004.

[34] H. Iiduka and W. Takahashi, "Weak convergence of a projection algorithm for variational inequalities in a Banach space," Journal of Mathematical Analysis and Applications, vol. 339, no. 1, pp. 668-679, 2008.

[35] S. Kamimura, F. Kohsaka, and W. Takahashi, "Weak and strong convergence theorems for maximal monotone operators in a Banach space," Set-Valued Analysis, vol. 12, no. 4, pp. 417-429, 2004.

[36] L. Li and W. Song, "Modified proximal-point algorithm for maximal monotone operators in Banach spaces," Journal of Optimization Theory and Applications, vol. 138, no. 1, pp. 45-64, 2008.

[37] N. Petrot, K. Wattanawitoon, and P. Kumam, "A hybrid projection method for generalized mixed equilibrium problems and fixed point problems in Banach spaces," Nonlinear Analysis: Hybrid Systems, vol. 4, no. 4, pp. 631-643, 2010.

[38] C. Klin-eam, S. Suantai, and W. Takahashi, "Strong convergence of generalized projection algorithms for nonlinear operators," Abstract and Applied Analysis, vol. 2009, Article ID 649831, 18 pages, 2009.

[39] S. Saewan and P. Kumam, "A hybrid iterative scheme for a maximal monotone operator and two countable families of relatively quasi-nonexpansive mappings for generalized mixed equilibrium and variational inequality problems," Abstract and Applied Analysis, vol. 2010, Article ID 123027, 31 pages, 2010.

[40] K. Wattanawitoon and P. Kumam, “Generalized mixed equilibrium problems for maximal monotone operators and two relatively quasi-nonexpansive mappings," Thai Journal of Mathematics, vol. 9, no. 1, pp. 171-195, 2011.

[41] K. Ball, E. A. Carlen, and E. H. Lieb, "Sharp uniform convexity and smoothness inequalities for trace norms," Inventiones Mathematicae, vol. 115, no. 1, pp. 463-482, 1994.

[42] Y. Takahashi, K. Hashimoto, and M. Kato, "On sharp uniform convexity, smoothness, and strong type, cotype inequalities," Journal of Nonlinear and Convex Analysis, vol. 3, no. 2, pp. 267-281, 2002.

[43] W. Takahashi, Nonlinear Functional Analysis, Fixed Point Theory and Its Application, Yokohama Publishers, Yokohama, Japan, 2000.

[44] J. Diestel, Geometry of Banach Spaces-Selected Topics, vol. 485 of Lecture Notes in Mathematics, SpringerVerlag, Berlin, Germany, 1975.

[45] Y. I. Alber, "Metric and generalized projection operators in Banach spaces: properties and applications," in Theory and Applications of Nonlinear Operators of Accretive and Monotone Type, A. G. Kartsatos, Ed., vol. 178, pp. 15-50, Marcel Dekker, New York, NY, USA, 1996.

[46] I. Cioranescu, Geometry of Banach Spaces, Duality Mappings and Nonlinear Problems, Kluwer, Dordrecht, The Netherlands, 1990.

[47] B. Beauzamy, Introduction to Banach Spaces, and Their Geometry, Elsevier Science, Noth Holland, 2nd edition, 1995.

[48] H. K. Xu, "Inequalities in Banach spaces with applications," Nonlinear Analysis. Theory, Methods $\mathcal{E}$ Applications, vol. 16, no. 12, pp. 1127-1138, 1991.

[49] C. Zalinescu, "On uniformly convex functions," Journal of Mathematical Analysis and Applications, vol. 95, no. 2, pp. 344-374, 1983.

[50] S. Kamimura and W. Takahashi, "Strong convergence of a proximal-type algorithm in a Banach space," SIAM Journal on Optimization, vol. 13, no. 3, pp. 938-945, 2002.

[51] F. Kohsaka and W. Takahashi, "Strong convergence of an iterative sequence for maximal monotone operators in a Banach space," Abstract and Applied Analysis, no. 3, pp. 239-249, 2004. 
[52] W. Takahashi and K. Zembayashi, "Strong and weak convergence theorems for equilibrium problems and relatively nonexpansive mappings in Banach spaces," Nonlinear Analysis. Theory, Methods $\mathcal{E}$ Applications, vol. 70, no. 1, pp. 45-57, 2009.

[53] S. Zhang, "Generalized mixed equilibrium problem in Banach spaces," Applied Mathematics and Mechanics, vol. 30, no. 9, pp. 1105-1112, 2009.

[54] R. T. Rockafellar, "Monotone operators and the proximal point algorithm," SIAM Journal on Control and Optimization, vol. 14, no. 5, pp. 877-898, 1976.

[55] K. K. Tan and H. K. Xu, "Approximating fixed points of nonexpansive mappings by the Ishikawa iteration process," Journal of Mathematical Analysis and Applications, vol. 178, no. 2, pp. 301-308, 1993. 


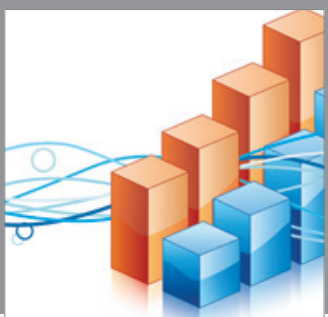

Advances in

Operations Research

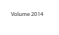

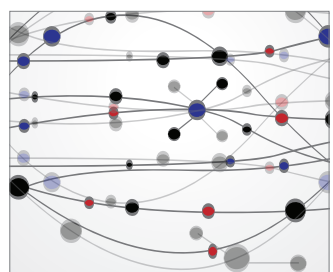

\section{The Scientific} World Journal
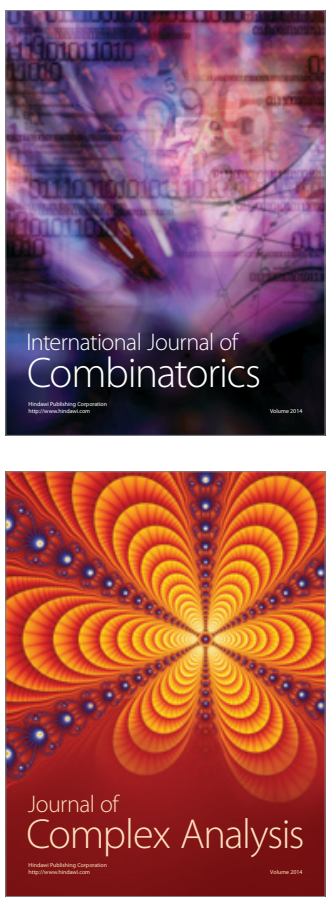

International Journal of

Mathematics and

Mathematical

Sciences
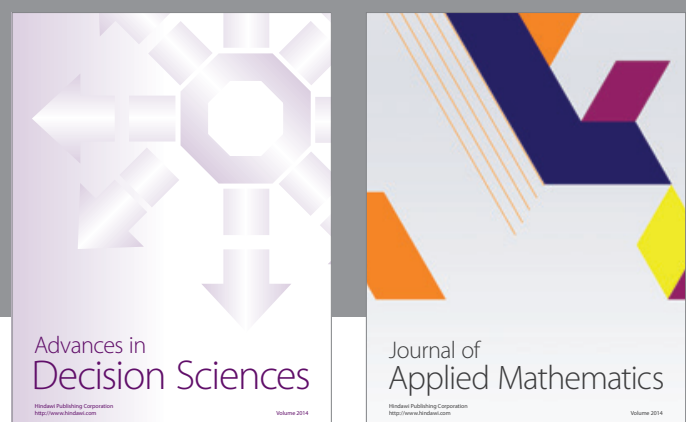

Journal of

Applied Mathematics
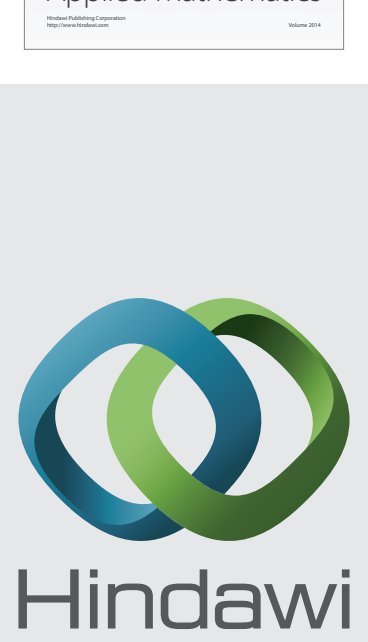

Submit your manuscripts at http://www.hindawi.com
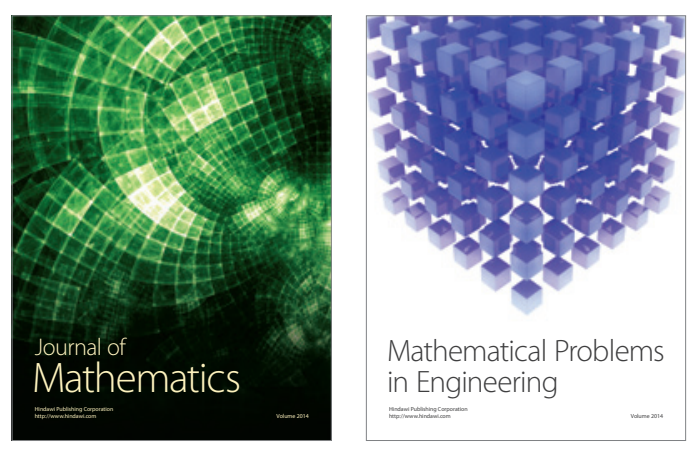

Mathematical Problems in Engineering
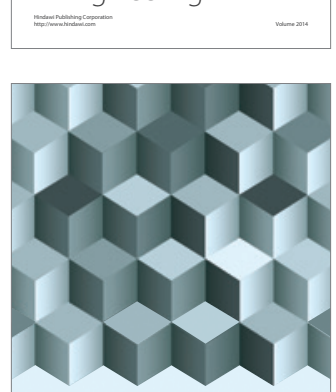

Journal of

Function Spaces
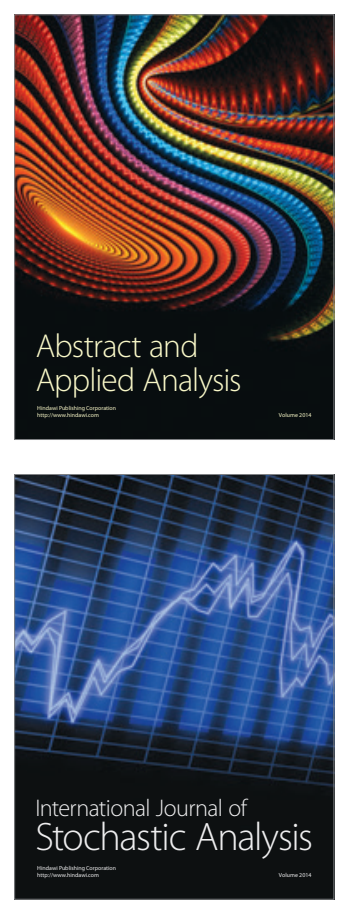

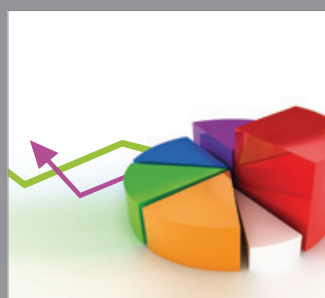

ournal of

Probability and Statistics

Promensencen
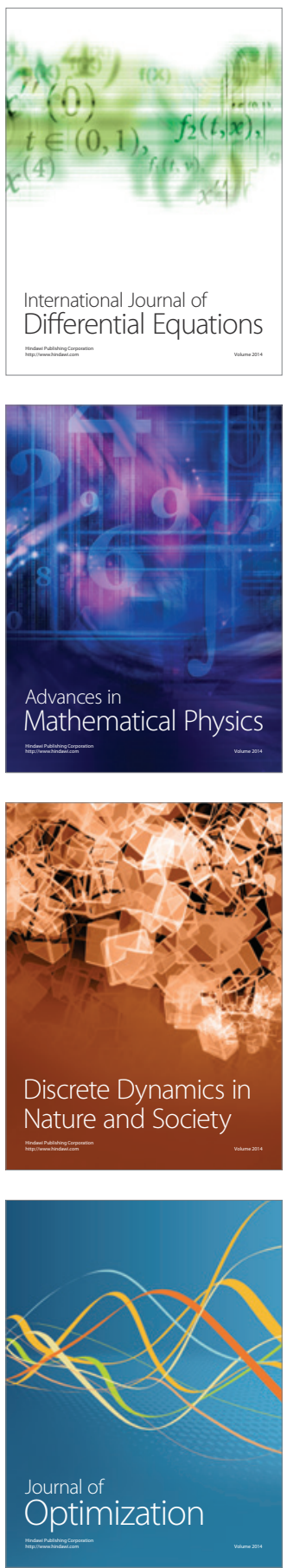